\title{
Introduction of emergency contraception in Bangladesh: Using operations research for policy decisions
}

\author{
M.E. Khan \\ Population Council \\ Sharif M.I. Hossain \\ Population Council \\ Md. Moshiur Rahman \\ Population Council
}

Follow this and additional works at: https://knowledgecommons.popcouncil.org/departments_sbsr-rh

Part of the Demography, Population, and Ecology Commons, Health Services Research Commons, and the International Public Health Commons

How does access to this work benefit you? Let us know!

\section{Recommended Citation}

Khan, M.E., Sharif M.I. Hossain, and Md. Moshiur Rahman. 2004. "Introduction of emergency contraception in Bangladesh: Using operations research for policy decisions," FRONTIERS Final Report. Washington, DC: Population Council. 


\title{
INTRODUCTION OF EMERGENCY CONTRACEPTION IN BANGLADESH: Using Operations Research for Policy Decisions
}

\author{
M.E. Khan \\ Population Council, India \\ Sharif Mohammed Ismail Hossain \\ Population Council, Bangladesh \\ Moshiur Rahman \\ Population Council, Bangladesh
}

December 2004

This study was funded by the US AGENCY FOR INTERNATIONAL DEVELOPMENT (USAID) under the terms of the Frontiers in Reproductive Health Cooperative Agreement Number HRN-A-00-98-00012-00, and Population Subcontract Number CI01.65A and In-house Project 580013025 453. The opinions expressed herein are those of the authors and do not necessarily reflect the views of USAID. 


\section{ACKNOWLEDGEMENTS}

Indeed it is a pleasure to acknowledge the collaboration and useful contributions made by the Directorate of Family Planning, Government of Bangladesh, Pathfinder International/RSDP, John Snow Incorporation/UFHP and the Population Council in carrying out this study. We would also like to thank district and thane level officials and all the providers who were partners in implementing the study. Providers and staff of FWCs, CWFD clinics and Sawnirvar Bangladesh clinics also played a critical role in this work.

The authors are particularly thankful to Dr. Jahiruddin Ahmed, former Director (MCH Services) and Line Director (ESP-RH), Directorate of Family Planning, Government of Bangladesh, for his guidance and continued support at every step of the study. Besides being an active collaborator from the Directorate, his role as Chairperson of the Project Management Committee was also very productive.

Other senior officials of the Directorate who contributed significantly in initiating and implementing the project include Mr. D. N. Nath, the then Director General of the Directorate of Family Planning, who assisted in initiating the study and the late Dr. S. M. Kamal, the then Director (MCH Services) and Line Director (ESP-RH), who extended his support to the study after taking over the position of Dr. Jahiruddin Ahmed.

Thanks are due to Dr. Mirza A. H. M. Barek, Deputy Director (Services) and Program Manager (FPS), Dr. Bishnupada Dhar, Assistant Director (Services) and Deputy Program Manager (I\&P), Directorate of Family Planning, and Dr. Mujibur Rahman, former ADCC, Tangail, for their sincere and sustained support of the study. We would also like to thank the authorities and faculty of Family Welfare Visitor Training Institute (FWVTI), Tangail for their role in providing training and space during the study.

Special thanks are due to Dr. Shabnam Shahanaz, Regional Director, Marie Stopes International, the then former Deputy Director (Program Operations), Pathfinder International for her active role in implementing and continued support for the study.

Lastly, thanks are due to our colleagues and friends from FRONTIERS. In the Population Council office in Bangladesh, Dr. Ubaidur Rob, Country Director, Mr. Dipak Shil, Office Manager, and Mr. Tapon Bose, Administrative Assistant and Secretary, ensured smooth functioning and logistic support in the implementation of the study. 


$\begin{array}{ll}\text { ABBREVIATIONS } \\ \text { BCC } & \text { Behavioral Change Communication } \\ \text { BDHS } & \text { Bangladesh Demographic and Health Survey } \\ \text { CBD } & \text { Community Based Distribution } \\ \text { CMW } & \text { Currently Married Women } \\ \text { CTU } & \text { Contraceptive Technology Updates } \\ \text { CWFD } & \text { Concerned Women for Family Development } \\ \text { DFP } & \text { Directorate of Family Planning } \\ \text { EC } & \text { Emergency Contraception } \\ \text { ECP } & \text { Emergency Contraceptive Pill } \\ \text { FGD } & \text { Focus Group Discussion } \\ \text { FP } & \text { Family Planning } \\ \text { FWVTI } & \text { Family Welfare Visitor Training Institute } \\ \text { IUD } & \text { Intra-uterine Device } \\ \text { JSI } & \text { John Snow Incorporation } \\ \text { MOHFW } & \text { Ministry of Health and Family Welfare } \\ \text { MR } & \text { Menstrual Regulation } \\ \text { NGO } & \text { Non Governmental Organization } \\ \text { NIPORT } & \text { National Institute for Population, Research and Training } \\ \text { OCP } & \text { Oral Contraceptive Pill } \\ \text { OR } & \text { Operations Research } \\ \text { UPI } & \text { Unprotected Intercourse } \\ \text { USAID } & \text { United States Agency for International Development } \\ & \\ \end{array}$




\section{EXECUTIVE SUMMARY}

Unwanted pregnancies constitute about one-third of the total pregnancies each year in Bangladesh. The Directorate of Family Planning, Population Council, Pathfinder International and John Snow Incorporated collaborated to conduct this OR study to assess the acceptability and feasibility of providing emergency contraception pills (ECP) as a backup support to existing family planning methods. The study was implemented in 12 health clinics in two districts of Bangladesh. Among the 12 clinics, eight were intervention clinics, while the remaining four were control clinics. The intervention, which consisted of the provision of information and services on ECP, was provided for nine months from March 2001 to November 2001.

The study tested the relative effectiveness of two alternative service delivery models for providing ECP. In the first study group (on-demand), all family planning clients except IUD, implant and sterilization acceptors received counseling and a brochure on ECP. They were asked to come back to the clinic for ECP supplies, if needed. In the second group (prophylactic), the women received the same information services but, in addition, were provided with two packets of ECP to use during an emergency. The third group was the control group, without any intervention.

The study revealed that unprotected intercourse is common (i.e., at least once a year) and women even within marriage do not have much control over their own body and sexuality. Common reasons for unprotected intercourse include: condom failure, missing pills or injections, occasional shortage of pills, unplanned sex, forced sex by partners and non-use of family planning. Knowledge of ECP, both among women and service providers, was nonexistent before the intervention.

The study demonstrated that all categories of health providers, including NGO outreach workers, could be effectively trained to provide ECP services. The evaluation of training and ECP services provided by the workers showed that more than 90 percent of the workers had assimilated the important points of ECP use and were able to instruct their clients about the use of the method correctly.

The study demonstrated high acceptability of ECP. About 65 percent of the women, who were aware of ECP, did not want any children in the immediate future and had unprotected intercourse, reported use of ECP. Among the two delivery models tested, the model providing ECP as a prophylactic was far more successful in meeting the needs of the clients for ECP than the model which provided ECP on-demand after unprotected intercourse occurred. In the former case, 75 percent of the clients in need, reported use of ECP as compared to 47 percent in the latter case. Logistic regression showed that the chance of ECP use was five times higher in the prophylactic area than in the on-demand area. The multivariate analysis further revealed that programmatic variables were the key factors in determining the use of ECP. They included the provision of ECP as a prophylactic (odds ratio 5.3), strong educational support measured in terms of the provision and reading of the ECP brochure (odds ratio 4.7), and the use of a contraceptive method when unprotected intercourse occurred (odds ratio 5.9). Contextual variables like gender equity, empowerment of women and reported absence of violence by their husbands play facilitating roles and contributed significantly to the acceptance of ECP. In scaling 
up of ECP services in the National Family Planning Program, the programmatic factors, particularly strong IEC support, will need special attention.

Most of the women who used ECP returned to a regular contraceptive method after the use of ECP. Among the ECP users, use of contraceptive methods increased from 84 percent before ECP use to 91 percent after its use. Very few used ECP more than once in the 9 month reference period. These findings dispelled fears of repeated use of ECP and the use of ECP as a regular family planning method.

The study revealed that if ECP was used correctly, the success rate in avoiding unwanted pregnancy was extremely high (99 percent). It dropped to 90 percent if ECP was used incorrectly. Among those who did not do anything after unprotected intercourse, 13.4 percent became pregnant. Thus, correct use of ECP was found as the key factor in avoiding pregnancy from unprotected intercourse. The study, however, shows that only about half of the ECP users used it correctly. This point needs special attention during the introduction of ECP in the National Program. Furthermore, it was estimated that correct use of ECP could reduce abortion by 37 percent, which in turn, would contribute to reductions in maternal morbidity and mortality in the country.

The positive findings of the study have helped the MOHFW, Government of Bangladesh, to approve introduction of ECP in the National Family Planning Program. It has been decided that all the providers including outreach workers will dispense the method and the client will be charged Taka 8 for one packet of two pills of ECP (Postinor-2). 


\section{TABLE OF CONTENTS}

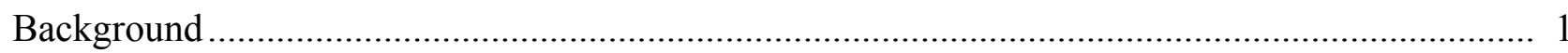

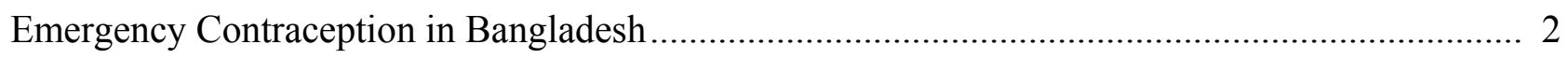

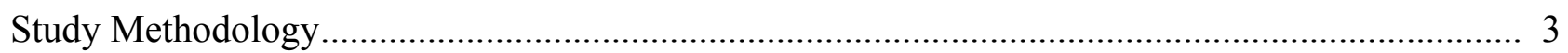

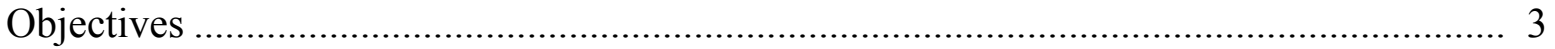

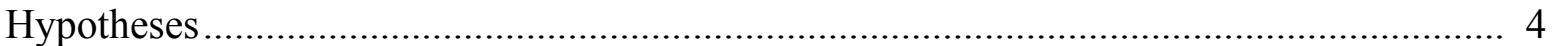

Other Research Questions ................................................................................................ 4

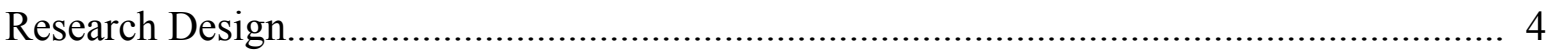

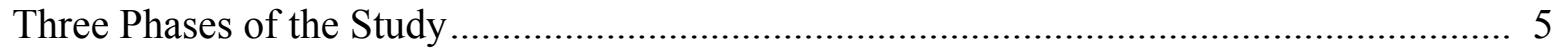

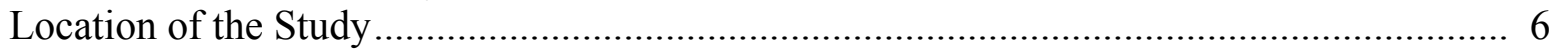

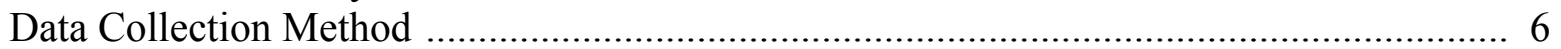

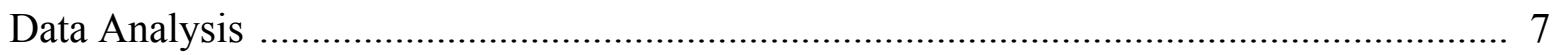

Interventions and Dependent Variables ......................................................................... 7

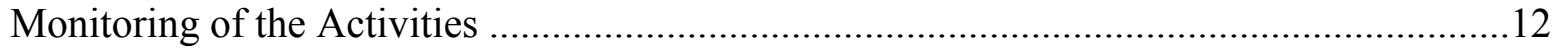

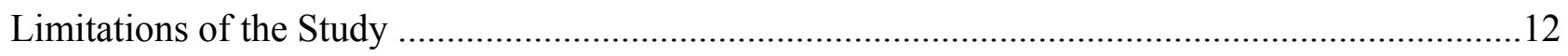

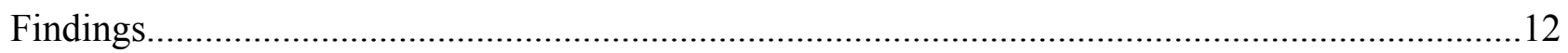

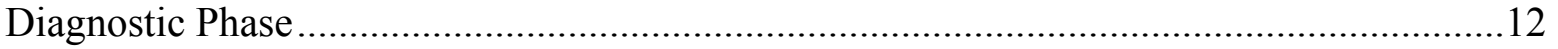

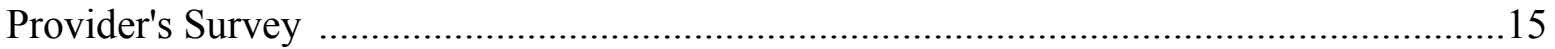

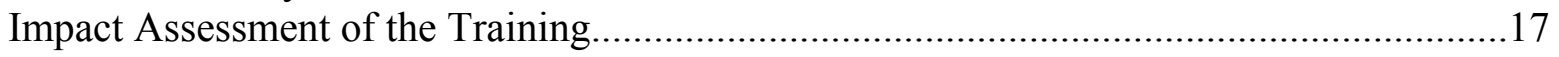

Impact Evaluation of Service Provision ........................................................................19

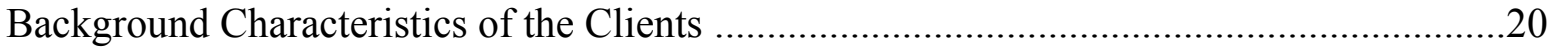

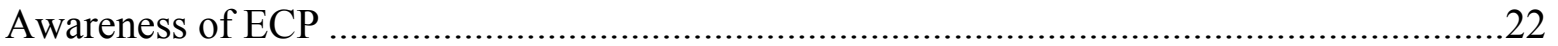

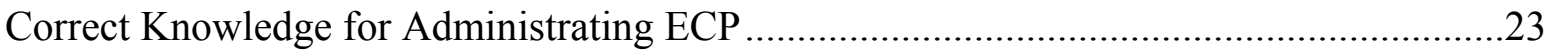

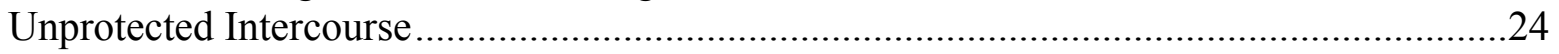

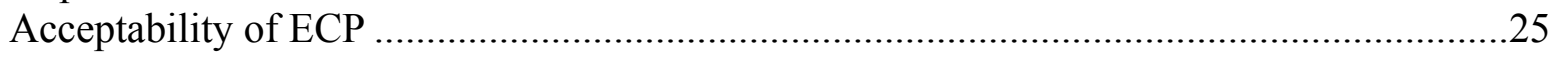

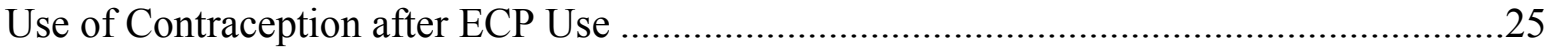

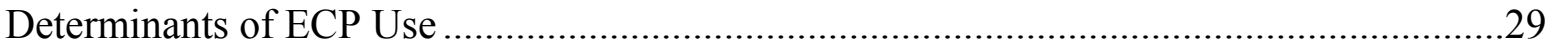

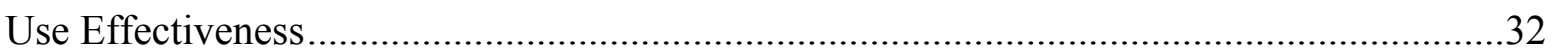

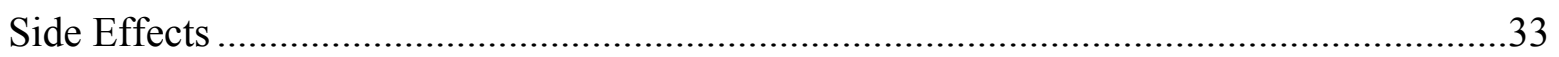

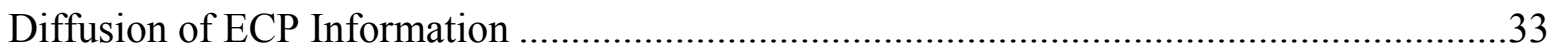

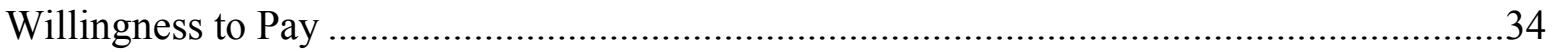

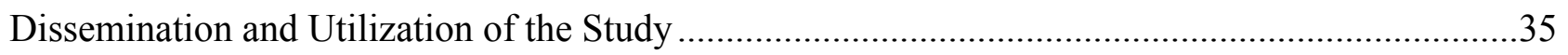

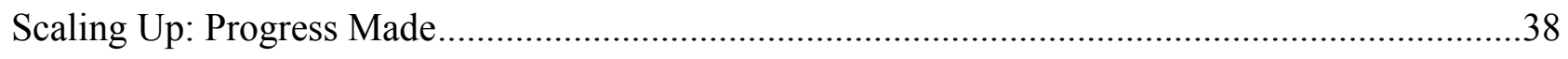

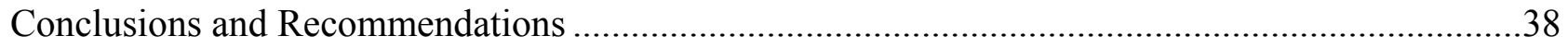

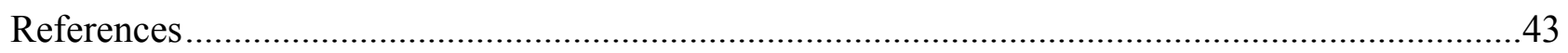

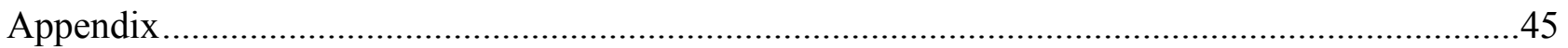




\section{List of Tables and Figures}

Table 1: $\quad$ Bangladesh Demographic and Family Planning Profile $\quad 1$

Table 2: $\quad$ Available OCP that could be Used as EC Pills 2

Table 3: $\quad$ Study Design $\quad 4$

Table 4: $\quad$ Background Characteristics of the Service Providers by Service Delivery Options 15

Table 5: $\quad$ Retention of Knowledge Gained about ECP 18

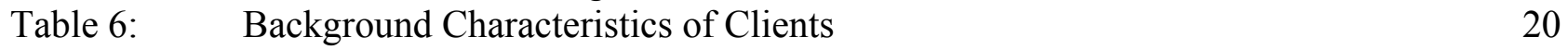

Table 7: $\quad$ Fertility Characteristics of Clients 21

Table 8: $\quad$ Sources and Knowledge about ECP 22

Table 9: $\quad$ Percentage who Gave Correct Answers by Service Delivery Options 23

Table 10: $\quad$ Correct Knowledge on ECP by Distribution of Brochure 23

Table 11: $\quad$ Unprotected Intercourse $\quad 24$

Table 12: $\quad$ Use of ECP 28

Table 13: $\quad$ Logistic Regression Analysis Using Socio-demographic Variables 29

Table 14: $\quad$ Logistic Regression Analysis Using Programmatic Variables 30

Table 15: $\quad$ Logistic Regression Analysis Using Gender Equity and Empowerment Variables 30

Table 16: $\quad$ Aggregate Logistic Regression Analysis $\quad 31$

Table 17: $\quad$ Reception and Dissemination of ECP Information 33

Table 18: $\quad$ Women's Willingness to Pay for the Method 34

Figure 1: $\quad$ Study Sites $r$

Figure 2: $\quad$ Provider's Training $\quad 9$

Figure 3: $\quad$ Client and Provider Brochures 11

Figure 4: $\quad$ Sample of ECP Packets 11

Figure 5: $\quad$ Inserts of Pill Packets 11

Figure 6: $\quad$ Perceptions of FP Workers on Emergency Contraceptive Pills 16

Figure 7: $\quad$ Percentage of Correct Responses Given by Providers who Participated in Pretraining, Immediate after Training and Post-training 18

Figure 8: $\quad$ Use of Contraception Before and After Using ECP 28

Figure 9: $\quad$ Willingness to Pay 35 


\section{BACKGROUND}

The 1999-2000 Bangladesh Demographic and Health Survey (BDHS) revealed that despite the increasing trend of contraceptive use in Bangladesh, there is still considerable scope for improvement. For example, one-third of the annual births (about 1.3 million) are unplanned, and the maternal mortality ratio is still quite high (370 per hundred thousands live births) (NIPORT, 2002). Approximately 20,000 maternal deaths occur every year in Bangladesh due to pregnancy and delivery-related complications, while many more women suffer from major physical and psychological morbidities. Although many types of contraceptives are widely available, 15 percent of the women or about 3.4 million couples still have unmet need for family planning services (see Table 1). Moreover, in the last 10 years, the total fertility rate has plateaued around 3.3 (BDHS, 2000). Abortion appears to be increasing, although the official estimate indicates only around 120,000 cases of menstrual regulation (MR)/abortion take place every year (Akhter, 1986 and Rochat et al., 1981). Unofficially, it is estimated that about 730,000 pregnancies

Table 1: Bangladesh Demographic and Family Planning Profile

\begin{tabular}{l|c|}
\hline Total population & 123 million \\
Women aged 10-49 & 37.5 million \\
Adolescent girls (10-19) & 13.6 million \\
Currently married women & \\
(CMW) in reproductive age & 22.8 million \\
CMW using any FP method & 12.3 million \\
Couples using traditional & \\
FP methods & 2.4 million \\
Couples with unmet need & 3.4 million \\
Couples not using any FP & \\
method & 10.5 million \\
Unwanted pregnancies & 1.3 million/year \\
\hline
\end{tabular}

Source: Census 2001; BDHS 1999-2000; BBS 2001 are terminated every year in Bangladesh (Singh et al., 1997).

The quality of MR/abortion services is reportedly poor and abortion-related complications contribute to about one-fourth of all maternal deaths in Bangladesh. It is estimated that approximately 5,000 women in Bangladesh die each year due to abortion-related complications (NIPORT, 2001 and Haidary, 1993). Because of the social and religious sensitivity attached to $\mathrm{MR} /$ abortion, women seek these services secretly, often from untrained providers under unsafe conditions. The available studies indicate that ineffective and harmful pregnancy termination practices are widespread (Haidary et al., 1996). 
Many of the abortion-related complications and deaths caused by repeated pregnancies could be avoided by promoting contraception, improving the quality of Menstrual Regulation (MR) or abortion and postabortion care services, and making emergency contraceptive pills (ECP) easily available and accessible to all those who need them to protect themselves from unwanted pregnancies due to unprotected intercourse. A recent WHO publication indicates that the use of ECP could reduce the induced abortion rate as much as 50 percent, which could directly reduce the maternal deaths linked to induced abortion (WHO, 2001). The Government has recognized that these issues need urgent attention to enhance the benefits of health and family planning services and to improve women's reproductive health. Introducing emergency contraception in the National Family Planning Program could substantially reduce unplanned pregnancies and as a result, the demand for MR/abortions would also decrease. Emergency contraception could also contribute significantly to reducing psychological stress and the health risks associated with unwanted pregnancies and abortions.

\section{EMERGENCY CONTRACEPTION IN BANGLADESH}

Emergency Contraception is relatively unknown both among providers and potential users in Bangladesh (Nahid et al., 1997). Although the oral contraceptive pills (OCP) available in the national family planning program can be used as an ECP (See Table 2), there is little knowledge about this important aspect of OCP among either the service providers or clients. Several studies show that unplanned pregnancies and maternal morbidities and mortalities could be reduced with the introduction of ECP in the program (ICEC, 2002).

\begin{tabular}{|c|c|c|}
\hline Brand Name & $\begin{array}{c}\text { Dose 1 } \\
\text { (within } 72 \\
\text { hours of } \\
\text { unprotected } \\
\text { intercourse) }\end{array}$ & $\begin{array}{c}\text { Dose 2 } \\
\text { (after } 12 \\
\text { hours of firs } \\
\text { dose) }\end{array}$ \\
\hline $\begin{array}{l}\text { Low-dose pills } \\
\text { Shukhi } \\
\text { Marvelon } \\
\text { Femicon } \\
\text { Nordette } 28\end{array}$ & 4 pills & 4 pills \\
\hline $\begin{array}{l}\text { Standard-dose } \\
\text { pills } \\
\text { Combination } 5 \\
\text { Ovastat } \\
\text { Lyndiol }\end{array}$ & 2 pills & 2 pills \\
\hline $\begin{array}{l}\text { Progestin-only } \\
\text { pills } \\
\text { Postinor } 2\end{array}$ & $\stackrel{\bullet}{1 \text { pill }}$ & 1 pill \\
\hline
\end{tabular}


In 1997, the Population Council organized a national workshop to discuss the potential of introducing ECP as a reproductive health intervention. The suggestion was welcomed by the participants but there was consensus that before introducing the method, a feasibility study should be carried out (Chowdhury et al., 1998). The National Technical Advisory Committee on contraception also suggested an operations research study to assess the acceptability of the method, the feasibility of its introduction in the National Family Planning Program and other operational issues before considering the introduction of ECP at the national level.

Accordingly, the Population Council took the lead and developed a protocol for conducting operations research to assess feasibility of introducing ECP in the National Family Planning Program. The proposal was developed in consultation with the Directorate of Family Planning. It was reviewed by the National Technical Advisory Committee on contraception and National Ethical Committee on Medical Research before the project was initiated in March 2000.

\section{STUDY METHODOLOGY}

\section{Objectives}

The broad objective of the study was to assess the need for and acceptability of ECP by women in Bangladesh. Besides, special attention was paid to develop, test and document the operational plans for introducing emergency contraception pills as backup support to existing family planning methods. More specifically, the study intended to:

- Determine the acceptability and appropriate use of ECP among married women

- Identify the most appropriate and cost-effective service delivery model to make ECP accessible

- Test and document how best ECP could be introduced without adversely affecting the use of other family planning methods.

\section{Hypotheses}

The following four hypotheses were tested:

- All service providers, including depot holders, can be trained to impart correct information about ECP to their clients

- Appropriate counseling by providers would ensure the correct and proper use of ECP 
- Counseling on ECP, together with its provision as prophylactic to women, will result in higher and appropriate use of ECP than counseling alone and providing ECP only ondemand

- Promoting and providing ECP as a backup support will not affect the use of other contraceptive methods.

\section{Other Research Questions}

Apart from the above hypotheses, the study also aimed to answer the following questions:

- What are the operational issues that the Directorate of Family Planning must address before introducing ECP in the program - content, technical details and duration of training, capability of workers to learn, retain and correctly impart information on ECP to their clients and the development of effective messages and IEC materials for providers and clients?

- Are rural and less educated women capable of learning to use the method correctly?

- What factors would facilitate the use of ECP after unprotected intercourse?

\section{Research Design}

A multi-factorial, control group, postintervention survey design was used to study the effects on the acceptability and use of ECP. The study tested the relative effectiveness of two alternative service delivery models for providing ECPs.

\begin{tabular}{|l|c|c|c|}
\hline \multicolumn{4}{|c|}{ Table 3: Study Design } \\
\cline { 2 - 4 } Interventions & \multicolumn{3}{|c|}{ Delivery Models } \\
\cline { 2 - 4 } & Demand & Prophylactic & Control \\
\hline $\begin{array}{l}\text { ECP } \\
\text { counseling and } \\
\text { brochure on } \\
\text { ECP }\end{array}$ & Yes & Yes & No \\
\hline $\begin{array}{l}\text { Two packets of } \\
\text { EC pills }\end{array}$ & No & Yes & No \\
\hline
\end{tabular}

On-Demand Delivery Model: In this case, all family planning clients except IUD, implant and sterilization acceptors, received counseling and a brochure on ECP. Further, women were advised to come back and take EC pills, free of charge, if they experienced unprotected sex.

Prophylactic Delivery Model: In this case, the clients received the same counseling about ECPs, a brochure on the method and in addition, two packets of ECPs as prophylactic, i.e. to use if the necessity arose.

The third study area was the control group where no ECP services were provided to any clients (Table 3). 


\section{Three Phases of the Study}

The study was carried out in three phases.

- Diagnostic and preparatory phase

- Intervention phase

- Impact assessment and dissemination of findings

In the first phase, using qualitative methods, information was collected on the existing practices that women use to avoid pregnancy if unprotected intercourse occurs; community perceptions about emergency contraception and their interest in using such a method, if it were made available. This information was used for developing training materials, guidance for counseling, educational aids and the questionnaire for the impact evaluation. Other activities accomplished in the first phase included: (a) assessment of family planning providers' knowledge of emergency contraception and their counseling skills, (b) development, pre-testing and finalization of brochures on ECP, and (c) the development of teaching aids including a trainer's manual on emergency contraception. In the intervention phase, after the training of providers, the provision of ECP services was introduced. In the third phase, the impact of the intervention was evaluated, findings were disseminated among different stakeholders and strategic planning was initiated to scale up the introduction of ECP in the National Family Planning Program.

\section{Location of the Study}

The study was carried out in two districts, Tangail and Mymensingh, located in the Dhaka division (see Figure 1). Twelve health clinics were selected for the study six each from the government and NGOs. Out of these, eight clinics were intervention sites, while the remaining four were control clinics.

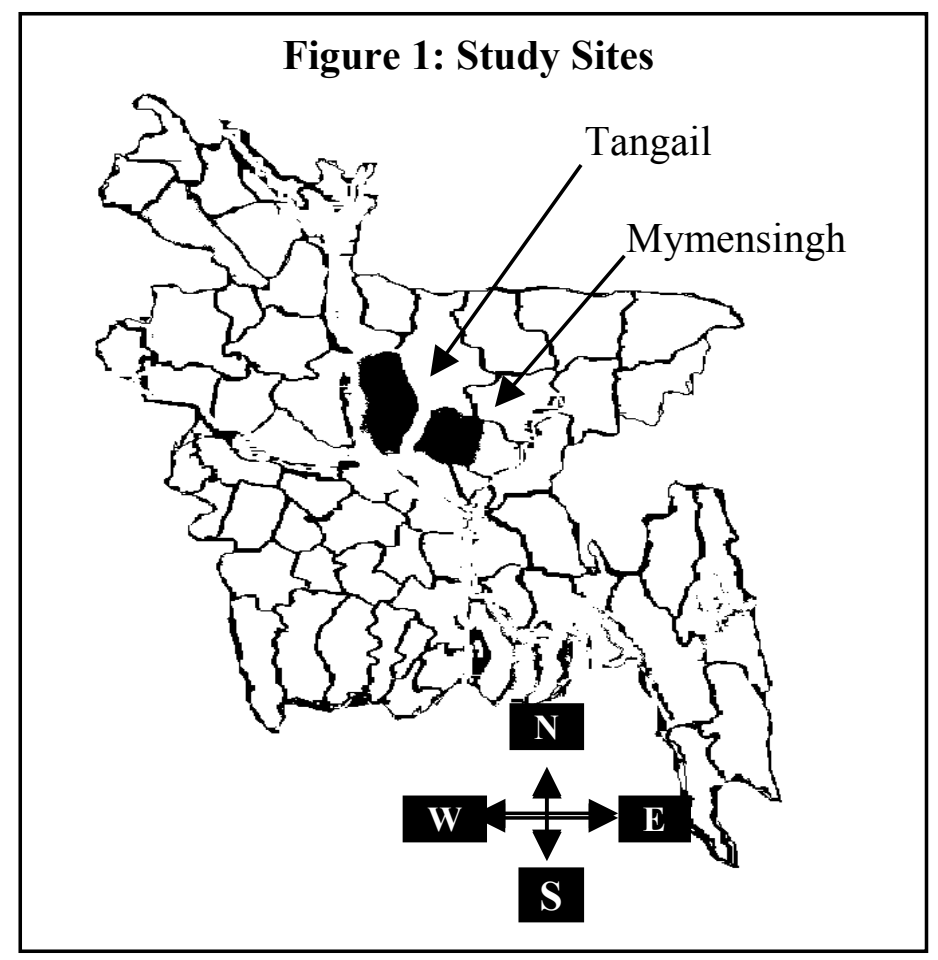


Selection of the locations and clinics was done in consultation with the Directorate of Family Planning and the two partners who helped in implementing the intervention of the study. In these locations, JSI and Pathfinder supported the work of NGOs under the bilateral USAID Program.

\section{Data Collection Method}

During the study, data were collected both using qualitative and quantitative approaches, including:

Community Perception Study: Focus Group Discussions (FGDs) and in-depth interviews of women were conducted to assess their perceived need of ECP, the contraceptive decisionmaking process and aspects of sexual behavior to understand the situations leading to unprotected sex. A total of 53 FGDs, 36 of women and 17 of men, were organized. Beside this, 54 married women were also interviewed in-depth.

Provider Surveys: To assess the impact of training and knowledge gained by the providers, three different sets of data were collected. First, a detailed baseline survey of all the 290 providers in the study area, using a structured interview schedule was carried out. This survey was completed well before the training was given. Second, brief pre-post training tests were conducted on the knowledge of ECP and ECP's proper use. These self administered tests were taken just before and immediately after the training sessions. A detailed survey of all the providers, four months after the training, was also conducted to assess retention of ECP knowledge taught in the training. Beside this, their views on introducing ECP in the program and experience of providing ECP were also collected.

Clients Survey: To assess the impact of the interventions and acceptability of ECP, a sample survey was conducted of 3,900 randomly selected women, from among those who were registered in the clinics and had given consent for the follow-up visit at their home for an interview. A total of 1,300 married women each from the prophylactic, on-demand and control areas were interviewed. 


\section{Data Analysis}

Appropriate techniques have been used for analyzing the different data sets, e.g., content analysis and descriptive analysis in the case of qualitative data, and comparison of simple percentage distribution in the case of provider and client surveys. Wherever appropriate, a z-test for proportions and a t-test have been applied to test the significance of the difference in the percentages and means, respectively. Logistic regression techniques were used to identify the determinants of emergency contraception use among those women who had experienced unprotected sex.

\section{Interventions and Dependent Variables}

Two interventions were made in the study areas, specifically:

- Training of the service providers

- Provision of ECP information and services under two different delivery models.

It was expected that these interventions would have an impact at two different levels:

1) Providers level: measured in terms of their gain and retention of knowledge about ECP, proper counseling to clients about the method, and the provision of ECP services

2) Clients (women) level: measured in terms of their gain in knowledge about ECP and its correct use if unprotected sex occurs.

Accordingly, the dependent variables considered in this study included:

- Increase in knowledge of providers about ECP after training

- Retention of knowledge gained about ECP, four months after the training

- Increase in awareness and knowledge of clients about ECP

- Use of ECP in case of need

\section{Intervention 1: Training of the Service Providers}

Preparatory Work: Before implementing the training, several preparatory steps were taken.

These included:

- Developing the training manual

- Planning and listing of learning objectives for each training session

- Developing overhead transparencies for each session (in Bangla)

- Developing guidelines for organizing "role plays" as a training tool 
- Developing, pre-testing and printing two ECP brochures, one each for the providers and clients (in Bangla)

- Discussing the objectives of the project with the trainers, the purpose of the training and the learning objectives for each session.

All the training materials developed were fully reviewed and standardized before actual use. Keeping in view the intention of scaling up of the ECP services in the National Family Planning Program, the attempt was made to institutionalize the training in a public training institute by involving their faculty in planning and implementing the training. The training program was carefully monitored and evaluated to answer operational issues raised earlier for introducing ECP in the National Family Planning Program (Box 1).

\section{Box 1: Operational Questions}

- What type of training is needed and for whom?

- What should be included in the training?

- What would be the impact of this training on workers' knowledge and their ability to communicate correct information to their clients?

- Will clients return to their regular contraceptive method after using ECP?

Focus of Training: To ensure that the entire contraceptive delivery system in the district has adequate knowledge about ECP and its role as backup support to contraceptive use, ECP training was organized for all Thana and district levels staff in the NGOs and the government's family planning delivery system. The trainees included all program managers, field supervisors, service providers and grass-roots workers.

While providers of all the three study areas received training, the detail and emphasis of the training sessions varied for each group. In the experimental areas for primary level providers, in addition to information on ECP, training included a contraceptive technology update (CTU) and a session on counseling skills (Box 2). Supervisors received additional training on

\section{Box 2: What was taught about EC}

- What is EC? When can it be used?

- Dose, interval between doses, time limit, effectiveness and mode of actions

- Side effects and their management

- Care in counseling on ECP to OCP users

- Return to regular family planning methods after ECP use

- Possible common questions and answers about ECP use

the importance of supportive supervision procedures for monitoring ECP work and using monthly meetings as an opportunity to clarify workers questions about ECP. The orientation of 
the program managers was more comprehensive and centered on the technical details of ECP and its role as a reproductive health intervention.

Training Organization: The outreach workers and their supervisors operating in the experimental areas received training at two different times. First, a two-day training was provided. One month after this training, a half-day orientation session was conducted to share their first month of experiences of providing EC services, clients' reactions to the method and to address their questions about ECP, if any (Figure 2). The providers in the control areas were given only a one-day, onetime training. They were given the same training as the providers in the experimental areas on CTU and counseling skills, but nothing was mentioned about ECP or the

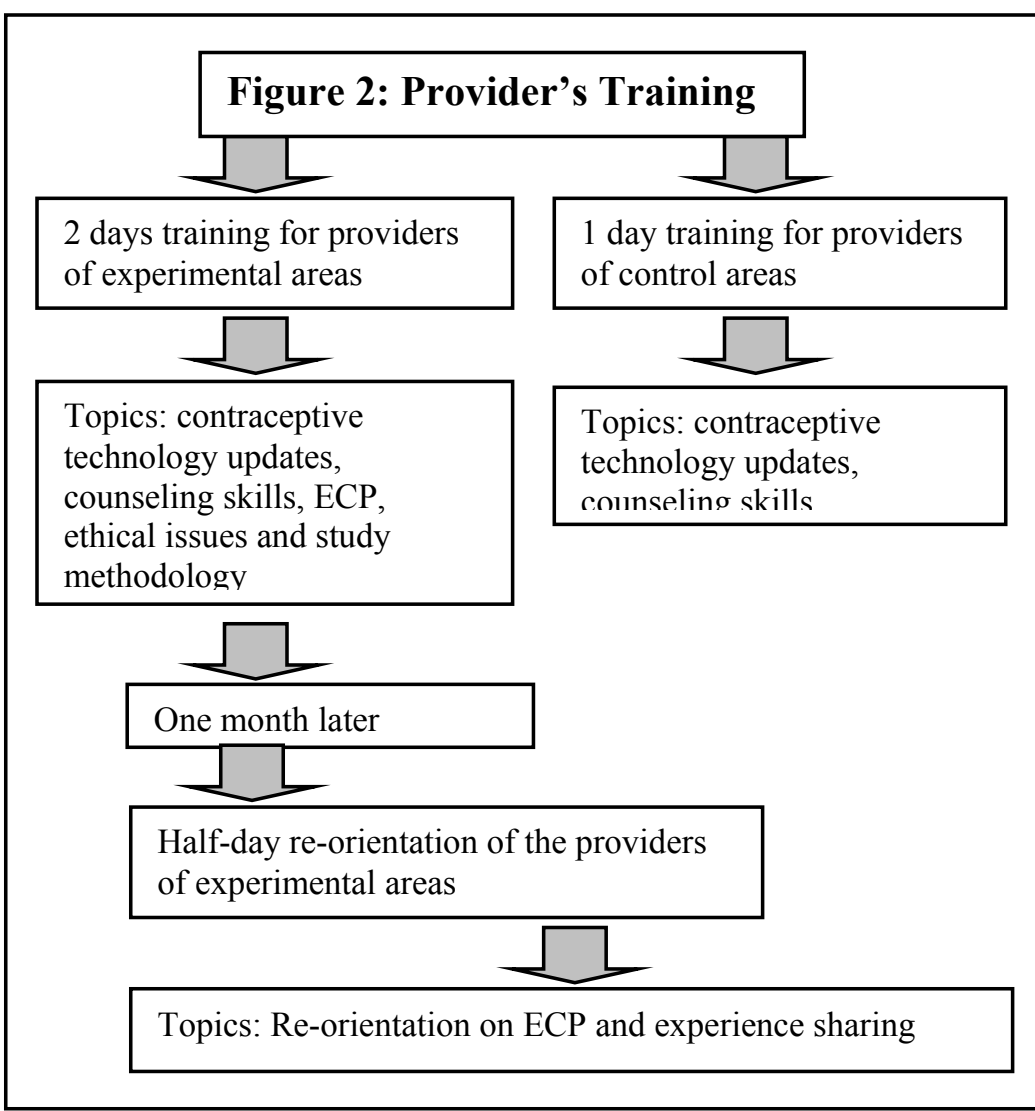
project activities. All training sessions were conducted in collaboration with the District Family Planning Office (DFPO) and the Family Welfare Visitor Training Institute (FWVTI) in Tangail. Selected faculties of the FWVTI and DFPO were fully involved in the planning and implementation of the training. Officials from the Directorate of Family Planning and district administration also participated in the training program as resource persons.

In the first training, each session had a time-bound presentation, role-play, and a question and answer session. The trainers had several rounds of discussion before finalizing the session's objectives and contents of the training. As a result, the trainers were clear about the learning objectives of each session and the expected outcomes of the session. All the workers were 
provided with a brochure on ECP developed both for the providers and clients. The second training session was conducted in a more informal environment and used a question and answer format. The workers were encouraged to share their experiences particularly about the acceptability of the method by the clients, types of questions they asked, problems they faced in addressing the client's questions and their own doubts about ECP, if any. Even though the second orientation on ECP was only a half-day long, it was found to be extremely useful because many workers had questions about the method (Khan et al. 2002). Clarification of their doubts helped in improving their knowledge about ECP and counseling with the clients.

\section{Intervention 2: Provision of ECP Information and Services}

In the experimental areas, all clients coming for family planning services except sterilization, implant and IUD were given information on ECP. Besides family planning clients, women who came for other services, but were also potential users of contraceptive methods were informed about ECP. As indicated in the Research Design section, the study tested two types of service delivery models. In one area family planning clients (women) were provided information and a brochure on ECP (Figure 3). They were asked to come back for the ECP supplies when needed, i.e. whenever unprotected sex occurs. In this report, this study site is referred to as the on-demand area. In the second area, the clients were provided with information, a brochure and two packets of ECP as a prophylactic to use during an emergency. We called this study site the prophylactic area. No ECP services were provided in the control area. Due to cultural sensitivity, unmarried women

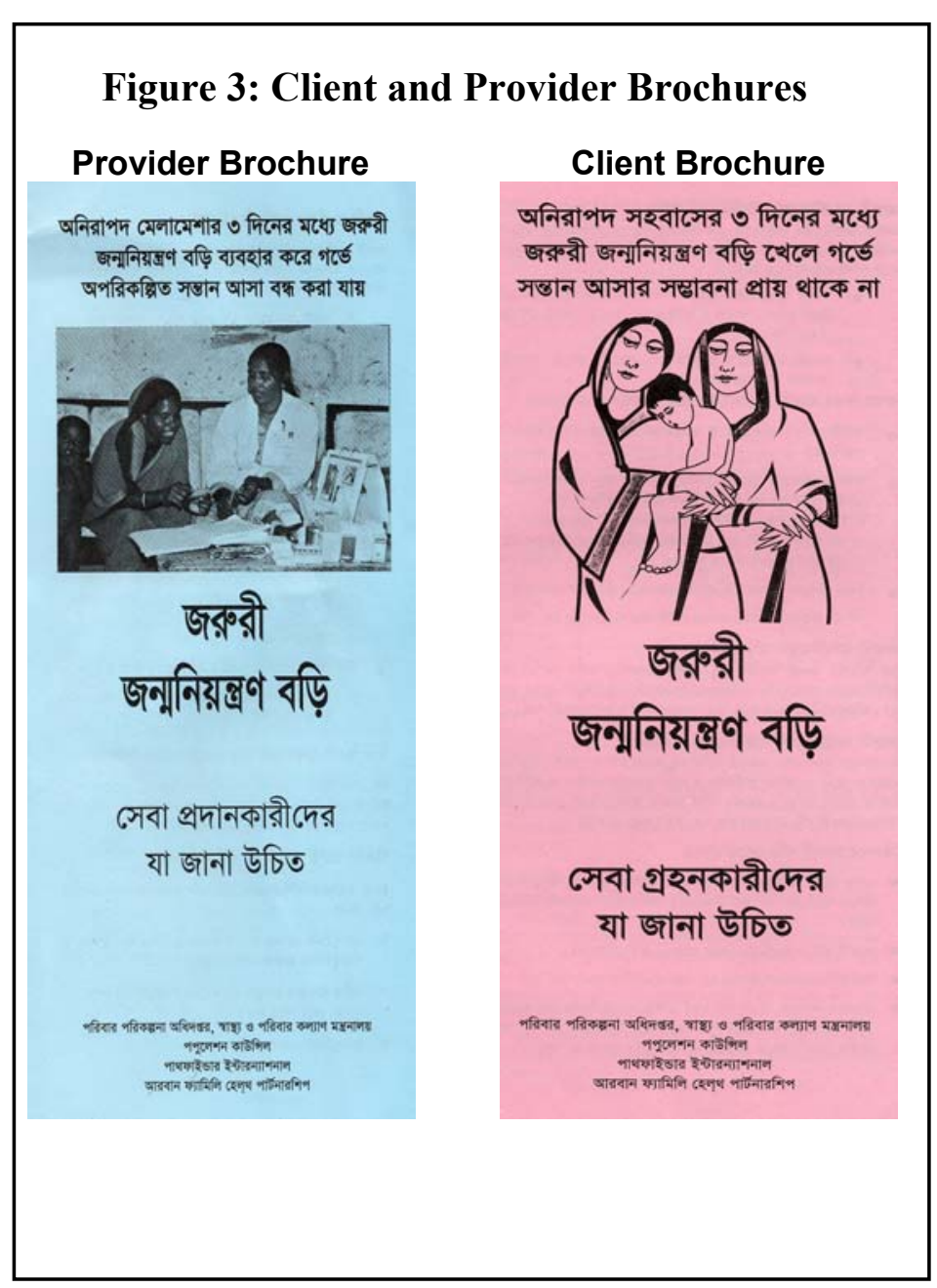


or adolescents were neither encouraged nor discouraged to get the information or ECP supplies. All the women who came for the services during the first six months after introducing ECP services were registered for the study if they agreed to participate in the study and gave their consent for the follow-up interview at their home. All clients, irrespective of whether they were willing to participate in the study, received other services from the clinics. During the registration period (November 2000 - March 2001) 8,451 women were provided with ECP services; 3,534 in the prophylactic area and 2,548 in the demand area. Out of these, 1,300 women from each area were chosen at random for interview.

EC Pills: For provision of ECP, a widely available oral contraceptive pill, Shukhi was repackaged as ECP. Shukhi is a low-dosed combined oral pill and available through the Government Family Planning Program. Eight pills divided into two doses of four pills each were inserted into the package. Information on how to use the pills was also printed and inserted in the packet (See Figures 4 and 5).

Figure 4: Sample of ECP Packets

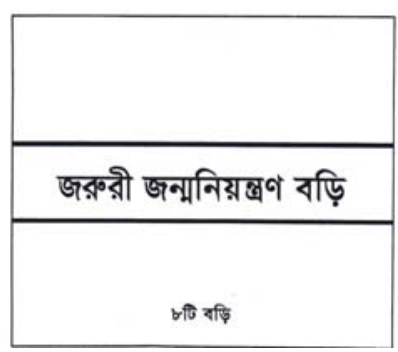

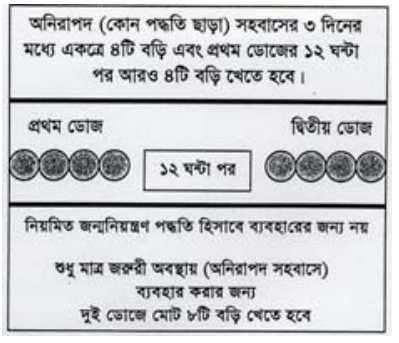

Figure 5: Inserts of Pill Packets

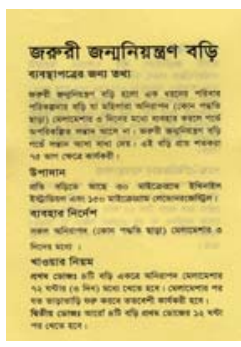

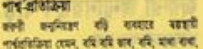

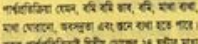

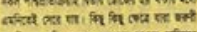

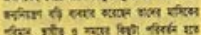
דim

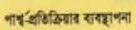

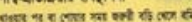

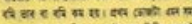

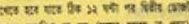

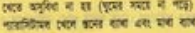




\section{Monitoring of the Activities}

The study used a decentralized monitoring process by providing responsibilities to each partner organization. Special attention was paid to strengthening the supportive supervision for monitoring project activities. Steps taken to monitor the program included:

- Checking knowledge of the workers and their provision of ECP services during each field visit by supervisors and program managers. To help supervisors with spot checking of ECP services, a checklist was prepared and provided to them.

- Discussion on the project activities and clarifications of their questions, if any, during the regular monthly meeting of the field staff/depot holders. During this meeting, clients' registration forms giving consent for participating in the study were also collected.

\section{LIMITATIONS OF THE STUDY}

The evaluation of the program revealed that many providers, despite close monitoring, did not complete the informed consent form properly and thus, in many cases the address noted was incomplete. The evaluation also revealed that after the initial provision of ECP, in the late phase of the study, providers did not inform all clients about ECP and/or provide the ECP brochure. These limitations must have influenced the results on the acceptability of ECP adversely. In scaling up, if adequate attention is paid to these issues, the acceptability of ECP perhaps will be still higher.

\section{FINDINGS}

\section{Diagnostic Phase}

Analysis of the qualitative data revealed that women did not have any knowledge of emergency contraception before the study. However, many women practice different traditional methods to protect themselves from unwanted pregnancy if unprotected intercourse occurs. Some of the frequently used traditional practices include passing urine after intercourse, standing up immediately after sex and walking or jumping, taking high doses of red pills (iron tablets) and an inappropriate dose of white pills (oral contraceptive). Some women drink salt water or tamarind water on an empty stomach to avoid pregnancy from unprotected intercourse. While asking women about the methods they used to prevent unwanted pregnancy from unprotected intercourse, one woman commented, 
"Apa (sister), I think you are married. Probably, you do not know the tricks. Do you know what I do? I just get up from bed after intercourse and start jumping. It does not allow 'baby' (semen) to go inside me. I am doing it for a long time and I never became pregnant. I have advised many of my friends and relatives about this method. They also practice it."

Another woman said,

"We pass urine immediately after unprotected intercourse"

Most women believe that unprotected intercourse is common. The reasons they listed include: condom failure (leakage or bursting), missing pills or injection date, occasional shortage of supply of pills, unplanned sex (unexpected visit of husband), and forced sex by their husbands. Most women felt that the availability of ECPs would be a great help to women since unprotected sex is common and they often do not have control over their sexual relationship.

One woman commented,

"My husband lives outside. Often he comes home unplanned. When he comes he has sex many times. Usually, he does not like to use condom. He says, I have come after a long time, let me enjoy it. If I resist he forces it. That month is full of worries and I eagerly wait for the next menses to come."

Yet another informant said,

"Sometime I do not have pills. Even in such situation my husband does not like to use condom. He says I can't wait to have sex till you get the method. What I can do in such situation?"

Women repeatedly mentioned about the worries and tension which they experience after unprotected intercourse. Their feelings are typically reflected in the following quote of one of the informants,

"Apa, you would not know worries of unwanted pregnancy. After unprotected sex the month becomes too long to pass (meant waiting for next menstrual bleeding is full of tension)."

The study also revealed that a substantial number of women use harmful traditional methods to terminate unwanted pregnancies. Such methods include inserting roots into the uterus, eating a caterpillar with a banana, and using other procedures from untrained providers. In general, both 
men and women believe that the incidence of MR/abortion is increasing, but the dependence on Kabiraj (traditional healers) has declined. None of the women in the focus group discussions could distinguish between MR and abortion. In Bangladesh, MR is considered as an "interim method of establishing non-pregnancy" and can be conducted within 10 weeks from the missed menstrual period. Before the procedure (MR), no pregnancy test is required to confirm pregnancy. While MR is legally approved, abortion is illegal and a punishable act.

In most of the FGDs, participants agreed that women would be willing to pay for ECP. In 44 out of 53 FGDs conducted, Taka 10-15 emerged as the consensus suggested price of the pills for one encounter of unprotected intercourse. One woman commented,

"..............Women have to go through a lot of tension and worries after each unprotected sex. They will love to have ECP, even if it cost Taka 20..........."

Another informant said,

"Listen apa (sister), paying Taka 15-20 is much easier than paying 200 or more after getting pregnant from unprotected sex. If I go to doctor they will charge 200 for 2 months' pregnancy and 300 for 3 months' pregnancy."

In 43 of the 53 FGDs, in general, the participants didn't feel that introducing emergency contraceptive pills would reduce the use of other family planning methods. Interestingly, in 39 FGDs some of the participants felt that the easy availability of emergency contraception pills might increase pre- or extramarital sex.

The diagnostic part of the study thus clearly revealed that emergency contraception is an unmet need within the family planning services. In the absence of ECP knowledge and desperate to avoid unwanted pregnancies from unprotected intercourse, women use various ineffective methods and in some cases resort to harmful practices. The qualitative data also demonstrated the extent of psychological stress which the women experience after having unprotected intercourse. This is well reflected in the comment of a woman who said "After unprotected sex the month becomes too long to pass". These were the reasons that during FGDs most participants felt that ECP would greatly benefit women and most of them were willing to pay for the method. These findings indicated that chances of acceptability of ECP, if introduced in the program, would be quite high. 
The information gathered from the qualitative research was efficiently used in outlining the training of the providers, developing teaching aids and in the development of the questionnaire for the impact evaluation.

\section{Provider's Survey}

Findings from the Baseline Survey: The total number of providers who participated in this study was 290 . They belonged to diverse groups, varying from trained paramedics having 18-36 months of formal professional training to Family Welfare Assistants and Depot Holders who did not have any formal training and often very little education (primary or 8th class pass). The background of the providers is presented in Table 4. As can be seen in the table, the background characteristics of the providers in the experimental and control area were very similar and the differences were not statistically significant. For instance, the mean age of the workers, proportion of female workers, and mean years of schooling were all quite similar in the experimental and control groups and the differences were not statistically significant.

A comparison of the background characteristics of the providers from the two experimental groups (prophylactic and ondemand) showed that the two experimental groups were also quite similar.

\begin{tabular}{|c|c|c|c|c|}
\hline \multicolumn{5}{|c|}{$\begin{array}{c}\text { Table 4: Background Characteristics of the Service } \\
\text { Providers by Service Delivery Options }\end{array}$} \\
\hline \multirow{3}{*}{$\begin{array}{c}\text { Selected } \\
\text { Characteristics }\end{array}$} & \multicolumn{4}{|c|}{ Service Delivery Options } \\
\hline & \multicolumn{2}{|c|}{ Experimental } & \multirow{2}{*}{$\begin{array}{c}\text { Total } \\
\text { Experimental }\end{array}$} & \multirow[t]{2}{*}{ Control } \\
\hline & Prophylactic & $\begin{array}{c}\text { On- } \\
\text { demand }\end{array}$ & & \\
\hline \multicolumn{5}{|l|}{ Area } \\
\hline Rural & 93.8 & 86.1 & 90.9 & 89.0 \\
\hline Urban & 6.2 & 13.9 & 9.1 & 11.0 \\
\hline \multicolumn{5}{|l|}{ Age (years) } \\
\hline$<25$ & 14.0 & 12.7 & 13.5 & 9.8 \\
\hline $25-29$ & 19.4 & 21.5 & 20.2 & 23.2 \\
\hline $30-34$ & 24.8 & 17.7 & 22.1 & 19.5 \\
\hline $35-39$ & 20.9 & 24.1 & 22.1 & 17.1 \\
\hline$>39$ & 20.9 & 24.1 & 22.1 & 30.5 \\
\hline Mean & 32.6 & 33.5 & 32.9 & 33.4 \\
\hline Median & 32 & 33 & 33 & 32 \\
\hline SD & 7.7 & 7.9 & 7.8 & 7.2 \\
\hline \multicolumn{5}{|c|}{ Sex of the provider } \\
\hline Female & 95.3 & 88.6 & 92.8 & 91.5 \\
\hline Male & 4.7 & 11.4 & 7.2 & 8.5 \\
\hline \multicolumn{5}{|c|}{ Provider's years of schooling } \\
\hline Illiterate & 2.3 & - & 1.4 & - \\
\hline $1-5$ & 8.5 & 20.3 & 13.0 & 11.0 \\
\hline $6-8$ & 42.6 & 16.5 & 32.7 & 28.0 \\
\hline $9-10$ & 27.1 & 26.6 & 26.9 & 32.9 \\
\hline $11-12$ & 10.1 & 21.5 & 14.4 & 13.4 \\
\hline Graduate & 8.5 & 12.7 & 10.1 & 12.2 \\
\hline Post Graduate & 0.8 & 2.5 & 1.4 & 2.4 \\
\hline Mean & 8.2 & 8.6 & 8.4 & 8.9 \\
\hline \multicolumn{5}{|c|}{ Received training } \\
\hline Yes & 98.4 & 92.4 & 96.2 & 91.5 \\
\hline No & 1.6 & 7.6 & 3.8 & 8.5 \\
\hline $\mathbf{N}$ & 129 & 79 & 208 & 82 \\
\hline
\end{tabular}


The main findings which emerged from the baseline survey of the providers are listed below:

- The providers are aware that unprotected sex is common in the community and many women come to them for advice after unprotected sex. On average, they receive 2-12 such requests from women per month.

- $\quad$ The providers also reported on the frequent unwanted pregnancies. The main reasons for these unwanted pregnancies, identified by the providers include the non-use of family planning methods ( 46 percent), missing pills ( 87 percent) or late due date of injection (31 percent), condom failure (74 percent), unexpected visit by husband (11 percent) and miscalculation of the safe period (12 percent).

- The majority of the providers believe that a substantial proportion of unwanted pregnancies are aborted. Apart from MR (93 percent), drugs from the pharmacy (52 percent), herbal medicine (58 percent) and insertion of roots or other harmful methods (56 percent) are frequently used by the women to abort unwanted pregnancies.

- $\quad$ Out of the 290 workers interviewed, only 64 (22 percent) were vaguely aware that Shukhi (OCP) could be used as an emergency contraception. Only four of them (1.4 percent) were aware of the correct dose, number of pills in each dose, the interval between the two doses and time limit within which the first dose of ECP must be taken. None mentioned any other brand of pills that could be used as ECP. Thus, overall knowledge about ECP was limited among the providers.

- Most of the providers (91 percent) supported the introduction of ECP in the Family Planning Program (Figure 6). Many felt that this service should have been made available already. The following gives a typical comment from workers about the usefulness of ECP:

"Many women used to approach us for advice after unprotected sex. Previously we were helpless. We used to say wait and see up to start of the next menstrual period. Now, we can advice them what to do. It's a useful method. The clients are happy that they can protect themselves from unwanted pregnancy. We are happy to be useful to them."

\section{Figure 6: Perceptions of FP Workers on Emergency Contraceptive Pills (percent)}

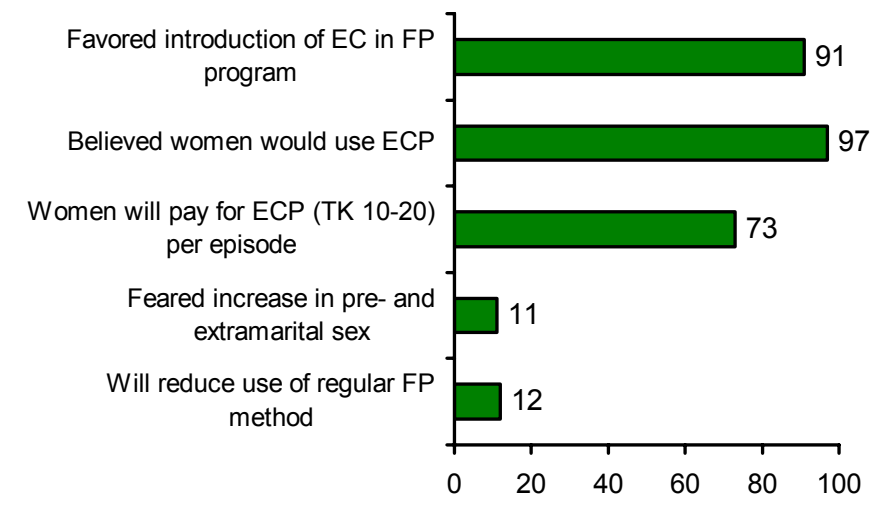

Source: Baseline survey of providers 
- Most of them believed that women would be willing to pay for ECP, if it was not provided free. The suggested price ranged between 10 and 15 Taka (US\$0.12-0.25) (See Figure 6).

- $\quad$ The survey also revealed prevailing misconceptions among the providers about OCP use. For instance, many of them $(82 \%)$ were not sure what could be done if a woman missed pills for two consecutive days. Similarly, many believed that long-term use of OCP could be harmful (e.g., cause sterility), and only 21 percent knew that OCP could be used for a woman's entire reproductive life.

- In general providers had poor counseling skills.

Thus, the baseline survey of providers demonstrated that few (1\%) of them had any knowledge about ECP. They all felt that if such a method were available, it should be immediately introduced in the National Family Planning Program. They believed that ECP would address a major unmet need of women and, therefore, women would be willing to pay for it. The providers also felt that the introduction of ECP in the program would help them provide services more effectively.

\section{Impact Assessment of the Training}

To answer whether or not providers of different levels and skills could be trained efficiently about ECP, and whether the training had the requisite impact, an evaluation was conducted at two times.

(1) Pre-post training tests

(2) Interview of all the providers four months after ECP training

The pre-post training tests were conducted by using a brief two-page self-administrated questionnaire, specially developed for testing the knowledge of ECP and its administration. Questions were also asked about OCP use and elements of counseling. The pre-training test was administrated just before starting the training, while the post-test was administrated immediately after completion of the two days of training. The comparison of individual responses documented the extent to which the training increased the knowledge of the providers about ECP. 
The detailed one-on-one interview of the providers four months after the training demonstrated the extent to which the providers are able to retain knowledge about ECP. The findings of the two evaluations are summarized in Table 5 and Figure 7.

\begin{tabular}{|c|c|c|c|c|c|}
\hline \multicolumn{6}{|c|}{$\begin{array}{l}\text { Table 5: Retention of Knowledge Gained about ECP - Percentage of Workers who } \\
\text { Mentioned Correct Answers to All Questions on OCP that Could be Used as ECP* }\end{array}$} \\
\hline \multirow[t]{2}{*}{ OCP Brand } & \multicolumn{2}{|c|}{ Immediate Evaluation } & \multicolumn{3}{|c|}{$\begin{array}{c}\text { Final Evaluation } \\
\end{array}$} \\
\hline & $\begin{array}{l}\text { Percentage } \\
\text { of workers } \\
\text { named the } \\
\text { specific brand } \\
\text { of OCP as } \\
\text { possible ECP }\end{array}$ & $\begin{array}{c}\text { Percentage of } \\
\text { workers with a } \\
\text { correct } \\
\text { answer }\end{array}$ & $\begin{array}{c}\text { Percentage of } \\
\text { workers named } \\
\text { the specific brand } \\
\text { of OCP as } \\
\text { possible ECP }\end{array}$ & $\begin{array}{c}\text { Percentage } \\
\text { of workers } \\
\text { with a } \\
\text { correct } \\
\text { answer }^{* *}\end{array}$ & $\begin{array}{l}\text { Retention } \\
\text { rate of } \\
\text { correct } \\
\text { knowledge }\end{array}$ \\
\hline Shukhi & 100 & 97 & 100 & 93 & 96 \\
\hline Marvelon & 82 & 88 & 100 & 73 & 83 \\
\hline Femicon & 96 & 97 & 100 & 85 & 88 \\
\hline Nordette 28 & 94 & 94 & 100 & 81 & 86 \\
\hline Ovastat & 83 & 79 & 100 & 84 & 105 \\
\hline $\mathbf{N}$ & 238 & & 245 & & \\
\hline
\end{tabular}

A post-training test conducted immediately after the two-day training showed a major change in their knowledge of ECP e.g. above 90 percent on most items (See Figure 7). In addition, the evaluation of the training program four months after the first training showed a high retention of their knowledge of ECP (See Figure 7). 


\section{Figure 7: Percentage of Correct Responses given by Providers who Participated in Pre-training, Immediate after-Training and Post-training (percent)}

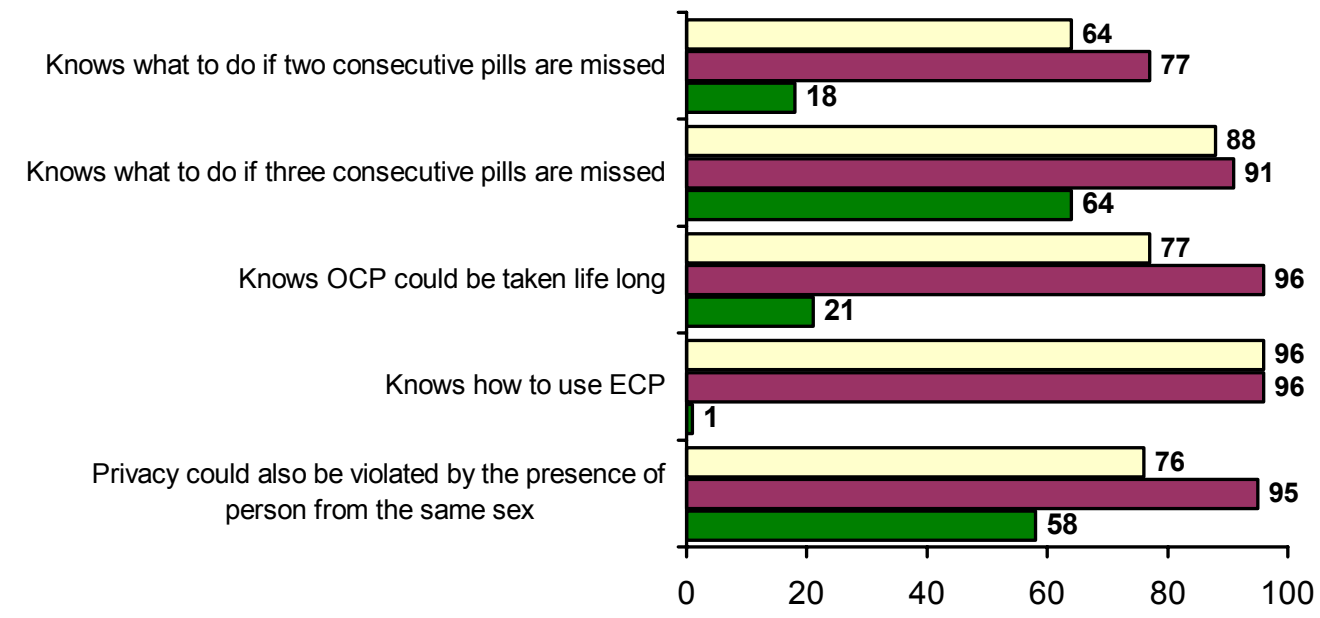

Practically all providers were able to tell how the ECP is correctly used. Besides that, most of them were able to name at least five brands of regular oral contraceptive pill commonly available in Bangladesh that could be used as ECP, if a dedicated product of ECP was not available. Further, up to 93 percent of the workers were able to give correct answers to all the questions on how the specific brand of oral contraceptive pills could be used as ECP. This included questions on the number of doses, number of pills per dose for that specific brand of OCP, interval between two doses and the time limit with which the first dose of ECP must be taken. A higher proportion of workers were able to give correct answers for those OC pills that they had in stock and were already distributing to clients.

The training of the service providers on ECP significantly increased $(\mathrm{p}<.05)$ the knowledge on the availability of a method that could prevent unwanted pregnancy after unprotected intercourse. At the 4-month evaluation almost 100 percent of the service providers in the experimental area knew that there is a method to prevent unwanted pregnancy after unprotected intercourse. The educational experience of the service providers and previous training in family planning method did not make any difference in acquiring correct knowledge of ECP use. This indicates that even Depot Holders, who generally have the lowest level of education, understand 
and correctly communicate well about the use of ECP. On the other hand, service providers in the control area remained largely unaware of ECP. Only 12 service providers $(14.6 \%)$ could mention that there are methods that could be used to protect against pregnancy from unprotected intercourse. However, only one $(1.2 \%)$ of them could mention all the four components of the correct use of ECP.

\section{Impact Evaluation of Service Provision}

To evaluate the impact of the interventions, the intake forms which were completed during the provision of information and services about ECP in all the study clinics were used as a sampling frame. All women who were provided services in the first six months of the intervention were included in the list. At each study site 1300 women were randomly selected for the interview. Because of the local contact with outreach workers, identifying the selected women was not difficult. Less than five percent were either not available or had moved out of the community during the interview period.

\section{Background Characteristics of Clients}

The study revealed that there was no significant difference on the client's background characteristics in the

\begin{tabular}{|c|c|c|c|c|}
\hline \multicolumn{5}{|c|}{ Table 6: Background Characteristics of Clients } \\
\hline \multirow{3}{*}{$\begin{array}{c}\text { Selected } \\
\text { Characteristics }\end{array}$} & \multicolumn{4}{|c|}{ Service Delivery Options } \\
\hline & \multicolumn{2}{|c|}{ Experimental } & \multirow{2}{*}{$\begin{array}{c}\text { Total } \\
\text { Experimental }\end{array}$} & \multirow[t]{2}{*}{ Control } \\
\hline & Prophylactic & $\begin{array}{c}\text { On- } \\
\text { demand }\end{array}$ & & \\
\hline \multicolumn{5}{|c|}{ Rural/urban distribution } \\
\hline Rural & 87.3 & 92.3 & 89.8 & 84.6 \\
\hline Urban & 12.7 & 7.7 & 10.2 & 15.4 \\
\hline \multicolumn{5}{|l|}{ Age (years) } \\
\hline$<20$ & 6.1 & 5.5 & 5.8 & 5.5 \\
\hline $20-29$ & 48.2 & 50.5 & 49.4 & 48.2 \\
\hline $30-39$ & 38.5 & 37.2 & 37.8 & 36.8 \\
\hline$>39$ & 7.2 & 6.7 & 7.0 & 9.5 \\
\hline Mean & 28.5 & 28.3 & 28.4 & 29.0 \\
\hline SD & 6.6 & 6.3 & 6.4 & 6.9 \\
\hline \multicolumn{5}{|l|}{ Husband's age } \\
\hline Mean & 36.3 & 36.2 & 36.3 & 36.5 \\
\hline SD & 7.8 & 7.6 & 7.7 & 7.8 \\
\hline \multicolumn{5}{|c|}{ Years of schooling (women) } \\
\hline Illiterate & 49.5 & 41.2 & 45.3 & 46.3 \\
\hline $1-5$ & 28.1 & 27.0 & 27.6 & 31.6 \\
\hline $6-10$ & 20.4 & 29.2 & 24.8 & 20.9 \\
\hline $11+$ & 2.0 & 2.6 & 2.3 & 1.2 \\
\hline Mean & 2.9 & 3.7 & 3.3 & 3.1 \\
\hline SD & 3.5 & 3.7 & 3.6 & 3.4 \\
\hline \multicolumn{5}{|c|}{ Years of schooling (husband) } \\
\hline Mean & 4.1 & 5.2 & 4.6 & 4.1 \\
\hline SD & 4.3 & 4.5 & 4.4 & 4.2 \\
\hline $\mathbf{N}$ & 1300 & 1300 & 2600 & 1300 \\
\hline \multicolumn{5}{|c|}{ Husband living arrangement } \\
\hline Lives with wife & 87.6 & 81.3 & 84.4 & 85.8 \\
\hline Lives elsewhere & 12.4 & 18.6 & 15.6 & 14.2 \\
\hline $\mathbf{N}$ & 1280 & 1266 & 2546 & 1289 \\
\hline
\end{tabular}
experimental and control 
areas in terms of age, husband's age, years of schooling (both of husbands and wives) and living arrangement (whether husband lives at home or stays elsewhere for work). The mean ages of the women in the experimental and control areas were 28 years and 29 years, respectively. Similarly, the mean age of client's husband was also almost identical (36.3 years vs. 36.5 years). Educational level of clients and their husbands in both the experimental and control areas was also quite similar. The mean years of schooling for women in the experimental and control areas were estimated to be 3.3 years and 3.1 years, respectively. The corresponding figures for husbands were 4.6 years and 4.1 years, respectively (See Table 6). Difference in mean years of schooling was not statistically significant.

In both experimental and control areas about 85 percent of the women were living with their husbands, while in the remaining cases, the husbands were living elsewhere for work (see

\begin{tabular}{|c|c|c|c|c|}
\hline \multicolumn{5}{|c|}{ Table 7: Fertility Characteristics of Clients } \\
\hline \multirow{3}{*}{$\begin{array}{c}\text { Selected } \\
\text { Characteristics }\end{array}$} & \multicolumn{4}{|c|}{ Service Delivery Options } \\
\hline & \multicolumn{2}{|c|}{ Experimental } & \multirow{2}{*}{$\begin{array}{c}\text { Total } \\
\text { Experimental }\end{array}$} & \multirow[t]{2}{*}{ Control } \\
\hline & Prophylactic & $\begin{array}{c}\text { On- } \\
\text { demand }\end{array}$ & & \\
\hline \multicolumn{5}{|c|}{ Number of living children } \\
\hline 0 & 2.9 & 5.6 & 4.3 & 3.8 \\
\hline 1 & 23.4 & 21.6 & 22.5 & 23.3 \\
\hline 2 & 33.8 & 33.5 & 33.7 & 33.2 \\
\hline 3 & 22.8 & 22.5 & 22.7 & 22.2 \\
\hline $4+$ & 17.1 & 16.8 & 16.9 & 17.5 \\
\hline Mean & 2.4 & 2.3 & 2.4 & 2.4 \\
\hline SD & 1.3 & 1.3 & 13 & 1.3 \\
\hline \multicolumn{5}{|l|}{ Number of sons } \\
\hline Mean & 1.2 & 1.1 & 1.2 & 1.2 \\
\hline SD & 0.9 & 0.9 & 0.9 & 0.9 \\
\hline \multicolumn{5}{|c|}{ Number of daughters } \\
\hline Mean & 1.2 & 1.2 & 1.2 & 1.1 \\
\hline SD & 1.1 & 1.0 & 1.0 & 1.1 \\
\hline \multicolumn{5}{|l|}{ Status of children } \\
\hline No pregnancy & 1.5 & 3.8 & 2.7 & 2.2 \\
\hline No live children & 1.4 & 1.8 & 1.6 & 1.5 \\
\hline No living son & 21.1 & 19.5 & 20.3 & 17.2 \\
\hline $\begin{array}{l}\text { No living } \\
\text { daughter }\end{array}$ & 23.9 & 23.4 & 23.7 & 27.3 \\
\hline $\begin{array}{l}\text { Has both living } \\
\text { son and daughter }\end{array}$ & 52.1 & 51.5 & 51.8 & 51.7 \\
\hline $\mathbf{N}$ & 1300 & 1300 & 2600 & 1300 \\
\hline \multicolumn{5}{|l|}{ Pregnancy } \\
\hline $\begin{array}{l}\text { Currently } \\
\text { pregnant }\end{array}$ & 5.1 & 6.4 & 5.7 & $4.5^{*}$ \\
\hline \multicolumn{5}{|l|}{ MR/abortion } \\
\hline Ever done & 8.3 & 8.1 & 8.2 & $6.7^{*}$ \\
\hline Mean & 0.09 & 0.09 & 0.09 & 0.07 \\
\hline SD & 0.33 & 0.33 & 0.33 & 0.38 \\
\hline $\mathbf{N}$ & 1280 & 1250 & 2530 & 1271 \\
\hline \multicolumn{5}{|c|}{ Methods of current contraception } \\
\hline Oral Pill & 58.7 & 60.5 & 59.7 & 51.0 \\
\hline Injectables & 25.9 & 20.2 & 23.2 & 33.1 \\
\hline Condom & 9.0 & 7.7 & 8.4 & 7.1 \\
\hline Copper T & 0.8 & 2.6 & 1.7 & 0.6 \\
\hline Implant & 0.4 & 0.3 & 0.3 & 0.8 \\
\hline Traditional & 5.2 & 8.7 & 6.8 & 7.4 \\
\hline $\mathbf{N}$ & 1074 & 986 & 2060 & 984 \\
\hline
\end{tabular}

$* \mathrm{p}<.05$

Table 6). 
An analysis of the fertility of the women with respect to the number of living children, sons and daughters, and current pregnancy status reveals that on all these parameters the study sites did not differ at all except that the proportion of women currently pregnant and the use of MR were slightly higher in the experimental area and the differences were statistically significant $(\mathrm{p}<.05)$ (See Table 7).

The percentage of women reporting current use of modern contraception was 73.7 percent in the experimental area and 70 percent in the control area. Details of the contraceptive use pattern are given in Table 7. While oral pills remain the main contraceptive method in both the experimental and the control areas, use of the injection was relatively higher in the control area (See Table 7).

\section{Awareness of ECP}

On probing, to assess how far the project succeeded in making the women aware of ECP, about 65 percent of the women in experimental area as compared to less than two percent in the control area had heard of ECP.

In the experimental area, a significantly higher percentage of women $(78 \%)$ in the

\begin{tabular}{|c|c|c|c|c|}
\hline \multicolumn{5}{|c|}{ Table 8: Sources and Knowledge about ECP } \\
\hline \multirow{3}{*}{$\begin{array}{c}\text { Selected } \\
\text { Characteristics }\end{array}$} & \multicolumn{4}{|c|}{$\begin{array}{c}\text { Service Delivery Options } \\
\end{array}$} \\
\hline & \multicolumn{2}{|c|}{ Experimental } & \multirow{2}{*}{$\begin{array}{c}\text { Total } \\
\text { Experimental }\end{array}$} & \multirow[t]{2}{*}{ Control } \\
\hline & Prophylactic & $\begin{array}{c}\text { On- } \\
\text { Demand }\end{array}$ & & \\
\hline \multicolumn{5}{|l|}{ Awareness of ECP } \\
\hline Heard about ECP & 78.4 & 51.2 & 64.8 & 1.5 \\
\hline $\mathbf{N}$ & 1300 & 1300 & 2600 & 1300 \\
\hline \multicolumn{5}{|c|}{ Sources of information } \\
\hline Service provider & 97.4 & 94.7 & 96.3 & 78.9 \\
\hline Brochure & 34.2 & 68.4 & 47.7 & - \\
\hline Others & 16.3 & 21.8 & 18.4 & 21.1 \\
\hline $\mathbf{N}$ & 1019 & 665 & 1684 & 19 \\
\hline \multicolumn{5}{|l|}{ Brochure } \\
\hline $\begin{array}{l}\text { Percentage } \\
\text { received brochure }\end{array}$ & 66.4 & 33.5 & 44.8 & - \\
\hline $\mathbf{N}$ & 1300 & 1300 & 2600 & - \\
\hline $\begin{array}{l}\text { Percentage read } \\
\text { the brochure }\end{array}$ & 29.2 & 51.3 & 37.7 & - \\
\hline $\begin{array}{l}\text { Percentage } \\
\text { reported } \\
\text { somebody else } \\
\text { read the brochure }\end{array}$ & 26.7 & 21.4 & 24.6 & - \\
\hline $\mathbf{N}$ & 863 & 538 & 1401 & - \\
\hline
\end{tabular}

prophylactic area were aware of ECP as compared to the on-demand area (51\%). Most of the women received information from service providers and/or from the ECP brochure, which was provided to them. 
Although all clients were supposed to get brochures, the evaluation showed that only about 45 percent of them had actually received it (See Table 8 ).

Slightly more than one-third of the women who had received the brochure reported that they had read the brochure. Another 25 percent who could not read it themselves had asked someone to read it to them. In about 50 percent of the cases the readers were health workers, followed by the husbands (26 percent), sisters or sister-in-laws (16 percent) and the remainder reported someone else like a neighbor/friend who read it to them.

\section{Correct Knowledge for Administrating ECP}

Probing on the procedure for administrating ECP showed that only about 12 percent of the women, 16 percent in the prophylactic area and only five percent in the demand area had completely correct

knowledge,

measured in terms

of all the four

components of ECP

use, i.e., number of

dose (two doses),

pills per dose (four

pills), interval

between doses (12

\begin{tabular}{|l|r|r|r|r|}
\hline \multicolumn{5}{|c|}{ Table 9: Percentage Who Gave Correct Answers by Service } \\
Delivery Options
\end{tabular}

hours) and time limit

within which the first

dose must be taken

(72 hours).

Knowledge about the individual components varied and the lowest was observed on the interval between doses

\begin{tabular}{|l|r|r|r|r|r|r|}
\hline \multicolumn{1}{|c|}{ Table 10: Correct Knowledge of ECP by Distribution of Brochure } \\
\cline { 2 - 7 } & $\begin{array}{c}\text { No. of } \\
\text { doses }\end{array}$ & $\begin{array}{c}\text { No. of } \\
\text { pills/dose }\end{array}$ & $\begin{array}{c}\text { Interval } \\
\text { between } \\
\text { doses }\end{array}$ & $\begin{array}{c}\text { Time } \\
\text { limit }\end{array}$ & $\begin{array}{c}\text { All } \\
\text { correct }\end{array}$ & $\mathbf{N}$ \\
\hline $\begin{array}{l}\text { Brochure was } \\
\text { given }\end{array}$ & 40.1 & 42.6 & 32.7 & 33.1 & 13.3 & $\mathbf{1 4 0 1}$ \\
\hline $\begin{array}{l}\text { Brochure was } \\
\text { not given }\end{array}$ & 20.5 & 22.8 & 14.1 & 16.6 & 2.8 & $\mathbf{2 8 3}$ \\
\hline $\begin{array}{l}\text { Brochure was } \\
\text { read by her }\end{array}$ & 45.6 & 48.5 & 37.9 & 45.5 & 18.4 & $\mathbf{5 2 8}$ \\
\hline $\begin{array}{l}\text { Brochure } \\
\text { read by other }\end{array}$ & 44.1 & 45.8 & 35.4 & 37.7 & 12.2 & $\mathbf{3 4 5}$ \\
\hline $\begin{array}{l}\text { Brochure was } \\
\text { read by her } \\
\text { and other }\end{array}$ & 45.0 & 47.4 & 36.9 & 39.6 & 15.9 & $\mathbf{8 7 3}$ \\
\hline
\end{tabular}


(See Table 9). Only about five percent knew that OCP also could be used as ECP.

All this demonstrates that the introduction of ECP must be accompanied by a well planned and a sustained educational campaign. In the present study, information on ECP was mainly provided by the service providers at the clinic, Depot Holders and Family Welfare Assistants in the community. The brochure on ECP was provided to women as part of counseling on the method. Further analysis revealed that correct knowledge of those who were given an ECP brochure was significantly higher $(13.3 \%)$ compared to those who were not given a brochure $(2.8 \%)(\mathrm{p}<0.05)$. This proportion further improved if the respondent read the brochure herself (18.4\%) or someone else read this brochure to her (12.2\%) (See Table 10).

\section{Unprotected Intercourse}

ECP is required only if unprotected sex has occurred and the women does not want to be pregnant. Thus, every woman was asked whether they had experienced any episode of unprotected intercourse (UPI) in the last nine months. The analysis revealed that out of 3,673 clients who had replied to the question, about 18 percent in the experimental area and 14 percent in the control area had experienced at least one unprotected episode of sex in the previous nine months. The mean number of episodes of unprotected intercourse in the last nine months was 0.8 and 0.9 in the experimental and control areas, respectively (See Table 11).

In about 50 percent of

the cases, unprotected intercourse was due to not using any family planning method $(48 \%$ in the experimental area and $68 \%$ in the control area), while in the remaining 50 percent of

\begin{tabular}{|l|r|r|r|r|}
\hline \multicolumn{4}{|c|}{ Table 11: Unprotected Intercourse (UPI) } \\
\hline \multirow{3}{*}{$\begin{array}{l}\text { Selected } \\
\text { Characteristics }\end{array}$} & \multicolumn{4}{|c|}{ Service Delivery Options } \\
\cline { 2 - 3 } & Prophylactic & $\begin{array}{c}\text { On- } \\
\text { demand }\end{array}$ & \multicolumn{1}{c|}{$\begin{array}{c}\text { Total } \\
\text { experimental }\end{array}$} & Control \\
\hline $\begin{array}{l}\text { Percentage of } \\
\text { women who } \\
\text { experienced UPI } \\
\text { in 9 months }\end{array}$ & 18.9 & 17.4 & 18.2 & 14.3 \\
\hline Frequency of Unprotected Intercourse in the Last 9 Months \\
\hline Mean & 0.66 & 0.88 & 0.77 & 0.87 \\
\hline SD & 1.9 & 2.3 & 2.1 & 2.3 \\
\hline $\mathbf{N}$ & $\mathbf{1 2 4 1}$ & $\mathbf{1 2 0 5}$ & $\mathbf{2 4 4 6}$ & $\mathbf{1 2 2 7}$ \\
\hline
\end{tabular}

cases it was due to the failure of FP methods e.g., missing a pill consecutively for three days (32\% experimental and 
$16 \%$ control), missing an injection due date (8\%) or leakage of the condom (7\%). Although less frequent, an unexpected visit (3\%) and forced sex by their husbands $(2 \%)$ were also mentioned as causes of unprotected sex.

\section{Acceptability of ECP}

At the aggregate level, of the 2,446 women in the experimental areas who replied to the question on unprotected intercourse, 444 (18.2\%) had experienced unprotected sex. Of these 444 women, 312 (70.3 percent) were aware of ECP. Of these 312 women, 41 (13.1\%) wanted a child and were dropped from the analysis. Of the remaining 271women, 176 (64.9\%) used ECP and 166 of them $(94.3 \%)$ reported that they succeeded in avoiding a pregnancy. Ten (5.7\%) women, despite using ECP, failed to avoid a pregnancy. Further analysis by considering only those women who had used ECP correctly (i.e., two doses, four pills per dose, 12 hours apart and well within 72 hours of unprotected intercourse) revealed that 98.8 percent had succeeded in avoiding pregnancy. Among those who had used ECP but not correctly, 9.8 percent had failed to avoid an unwanted pregnancy. This failure rate was still better than those who had unprotected intercourse and had done nothing or were not aware of ECP. In this case, out of 112 women, 18 women (16\%) reported an unwanted pregnancy. When the same analysis was done for the two experimental areas separately, the use of ECP was significantly higher in the prophylactic area $(75 \%)$ than in the on-demand area (47\%). Further, the proportion of women who used ECP

correctly was also higher in the prophylactic area (50\%) than in the demand area (42\%). It might be the case that women could not clearly link the pregnancy to the reported episode of unprotected sex, but it appears that those who use ECP are less likely to have an unintended pregnancy in any case.

\section{Use of Contraception after ECP Use}

As ECP is not a regular method for contraception, the study had taken special care to prevent misuse. A key message of the training was that "it is a backup support to other FP methods and cannot be used as a regular contraceptive." It was emphasized during the training that clients must be encouraged to return to their previous method or to another contraceptive method of their choice. The study revealed that out of 194 women who used ECP, 163 (84\%) women were 
using some contraceptive when they had experienced unprotected intercourse. Out of these 156 (96\%) women returned to use their previous method or adopted a new family planning method. 


\section{$\underline{\mathrm{ECP}+\mathrm{OCP} \text { Users in Experimental Area }}$}

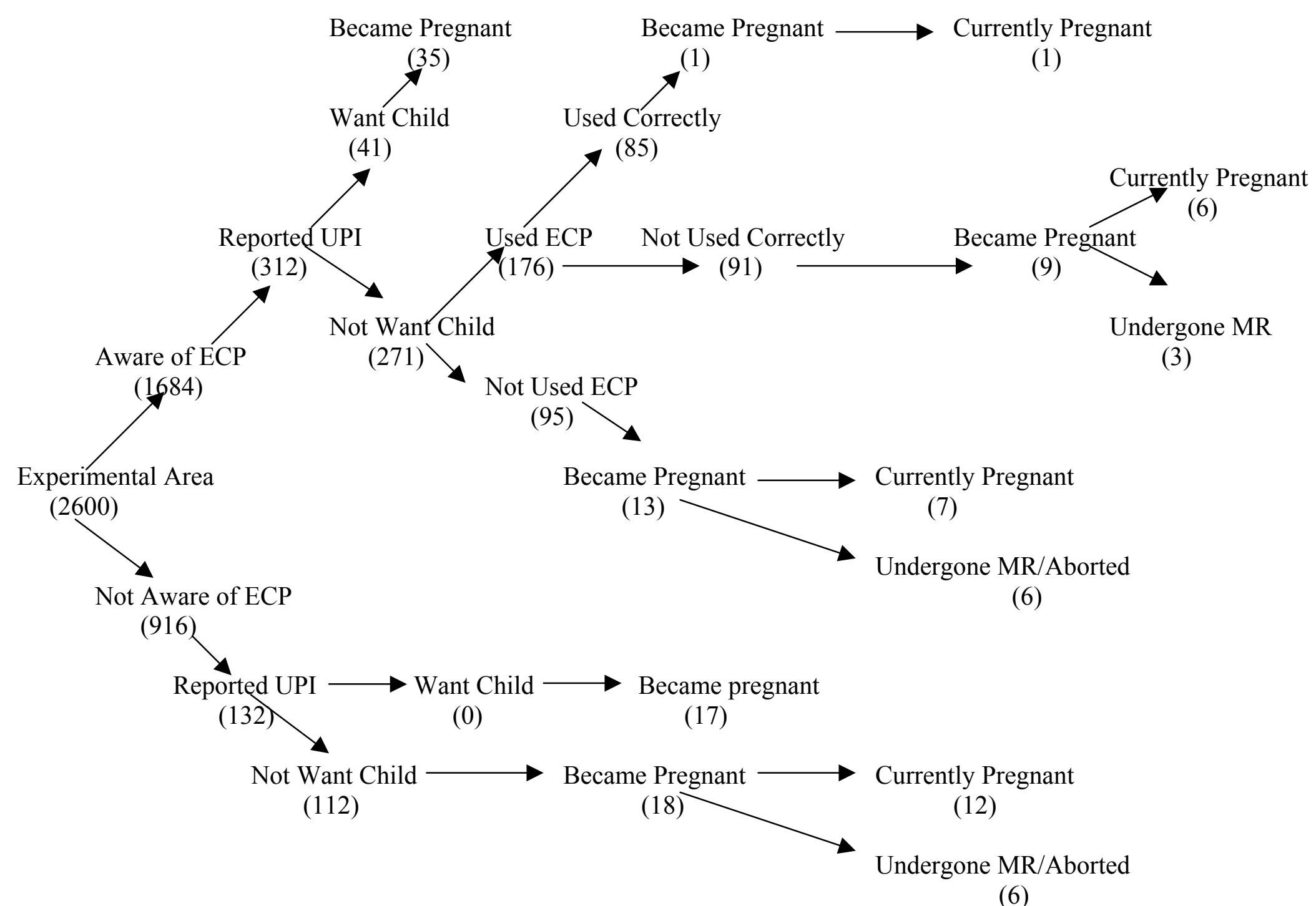




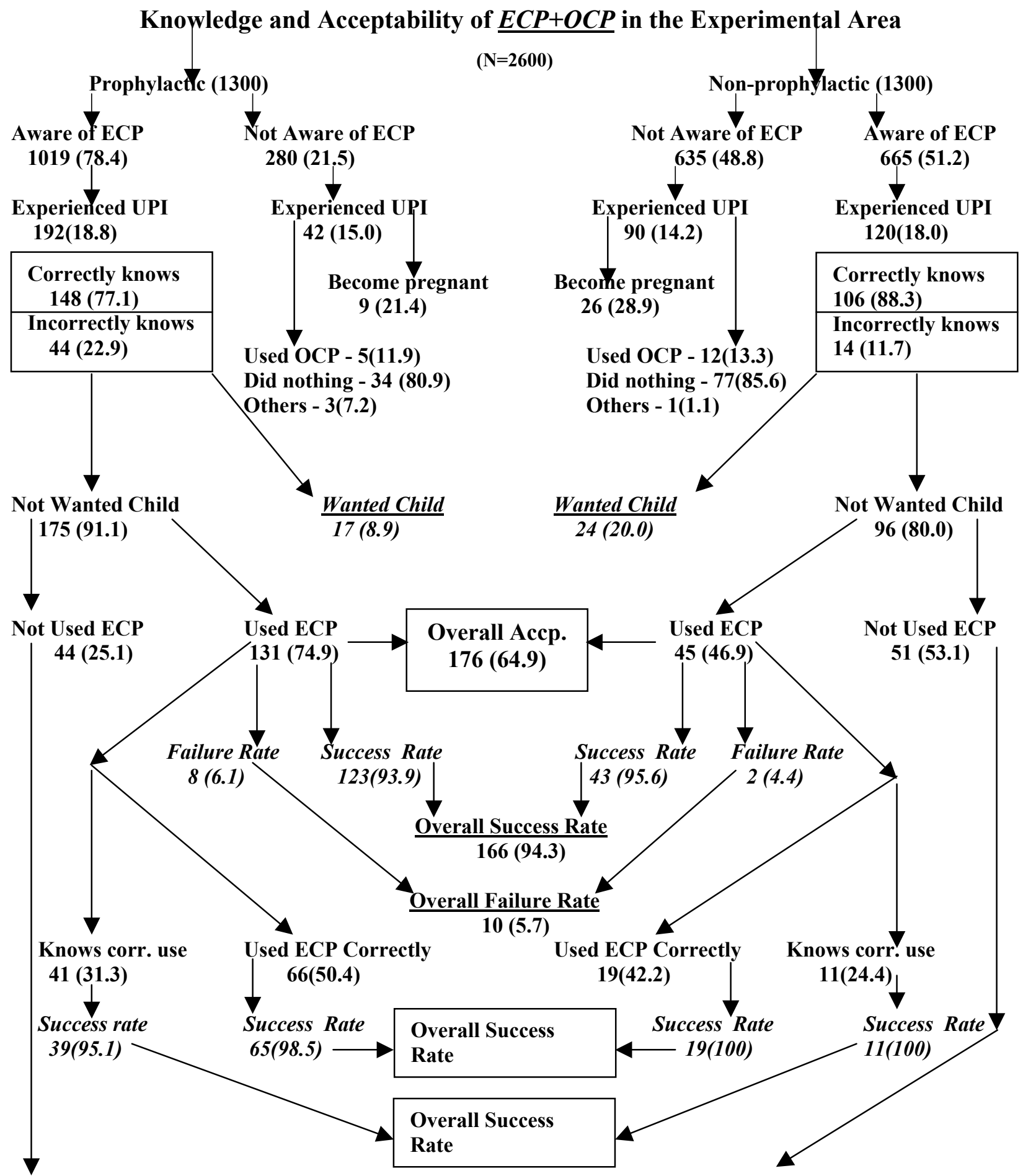

Reasons for not using ECP

Husband assured would not be preg. - 18(40.9)

Felt would not conceive $\mathbf{- 9 ( 2 0 . 5 )}$

Crossed the time limit - 3(6.8)

Fear of side effects - 4(9.1)

No access to ECP - 5(11.4)

Was busy - 1(2.3)

Others - 3(6.8)
Reasons for not using ECP

Husband assured would not be preg. - 20(39.2)

Felt would not conceive - 18(35.3)

Crossed the time limit - 3(5.9)

Fear of side effects - 3(5.9)

No access to ECP - 1(1.9)

Others - 6(11.8) 
More importantly, of the remaining 31 women $(16 \%)$ who at the time of unprotected sex were not using any family planning method, 21 women (68\%) adopted a method. Thus, out of the total 194 women who used ECP, 177 (91\%) adopted contraception subsequently (see Figure 8). This is an extremely encouraging finding and dispels the fear that women may adopt
Figure 8: Use of Contraception Before and After Using ECP (percent)

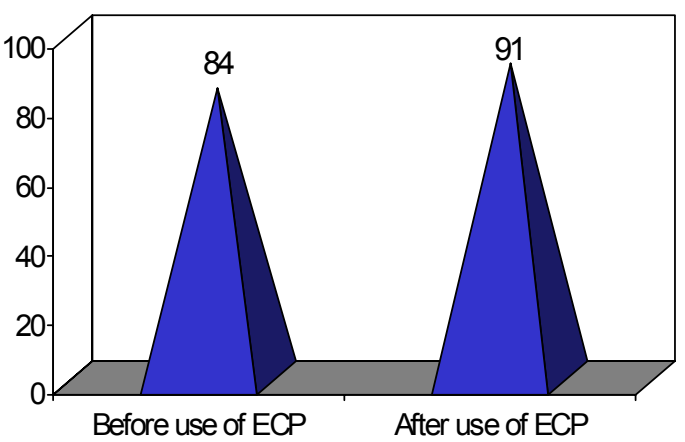

ECP as a regular contraceptive method.

There were a substantial number of women (25\% in the prophylactic area and $53 \%$ in the ondemand area) who did not use ECP despite being aware of the method. A probing of the reasons for not using ECP revealed that the three most common reasons were: husband's assurance that the UPI would not result in pregnancy $(40 \%)$, she believed that it was a safe (infertile) period $(28 \%)$, and fear of side effects (7\%) (Table 12). It is noteworthy that 9 percent of experimental and 8 percent of the control women use some combination and dosage of OCP as ECP without being aware of the required regimen for ECP.

\begin{tabular}{|c|c|c|c|c|}
\hline \multicolumn{5}{|c|}{ Table 12: Use of ECP* } \\
\hline \multirow{3}{*}{$\begin{array}{c}\text { Selected } \\
\text { Characteristics }\end{array}$} & \multicolumn{4}{|c|}{ Service Delivery Options } \\
\hline & \multicolumn{2}{|c|}{ Experimental } & \multirow{2}{*}{$\begin{array}{c}\text { Total } \\
\text { Experimental }\end{array}$} & \multirow[t]{2}{*}{ Control } \\
\hline & Prophylactic & $\begin{array}{c}\text { On- } \\
\text { demand }\end{array}$ & & \\
\hline \multicolumn{5}{|c|}{ Means of Protection } \\
\hline Used ECP & 67.5 & 36.5 & 56.4 & - \\
\hline $\begin{array}{l}\text { Used OCP as } \\
\text { ECP }\end{array}$ & 7.4 & 10.4 & 8.5 & 8.1 \\
\hline Did nothing & 25.1 & 53.1 & 35.1 & 91.9 \\
\hline $\mathbf{N}$ & 175 & 96 & 271 & 111 \\
\hline \multicolumn{5}{|c|}{ Reasons for Not Using ECP although had Unprotected Intercourse } \\
\hline $\begin{array}{l}\text { Husband's } \\
\text { assurance }\end{array}$ & 41.9 & 39.2 & 40.0 & - \\
\hline $\begin{array}{l}\text { Thought it was the } \\
\text { infertile period }\end{array}$ & 20.5 & 35.3 & 28.4 & - \\
\hline $\begin{array}{l}\text { Crossed the time } \\
\text { limit }\end{array}$ & 6.8 & 5.9 & 6.3 & - \\
\hline $\begin{array}{l}\text { Fear of side } \\
\text { effects }\end{array}$ & 9.1 & 5.9 & 7.4 & - \\
\hline $\begin{array}{l}\text { No access to ECP } \\
\text { at that time }\end{array}$ & 11.4 & 1.9 & 6.3 & - \\
\hline Was busy & 2.3 & - & 1.1 & - \\
\hline Others & 6.8 & 11.8 & 10.5 & - \\
\hline $\mathbf{N}$ & 44 & 51 & 95 & - \\
\hline
\end{tabular}


The fear that ECP will be used repeatedly in place of regular family planning method was also not supported by the study findings. In nine months intervention period about 91 percent of the women used ECP only once, 8 percent two times and 0.7 percent more than twice.

\section{Determinants of ECP Use}

The women who had experienced at least one episode of unprotected sex were separated and logistic regression analysis was done to identify the effects of selected socio-demographic, gender equity and programmatic factors on ECP use. Different combinations of variables were used to assess the key determinants. First, to identify the effects of socio-demographic, gender equity and programmatic factors, three separate logistic regression models were used. The dependent variable for all the models was the use of emergency contraception during the intervention period (nine months) measured as a binary variable. Among the women who had experienced unprotected sex, all who had used ECP to avoid pregnancy were assigned a value "1" otherwise "0". Results of the three regression models are presented below.

Socio-Demographic Variables as Determinant of ECP Use

The first model using six sociodemographic variables shows that neither education nor demographic variables influenced the use of ECP. The only variable which contributed significantly was the use of family planning method at the time when unprotected sex had occurred. The odds ratio of the variable shows that the probability of using ECP in case of unprotected sex is 6.7 times higher if at that

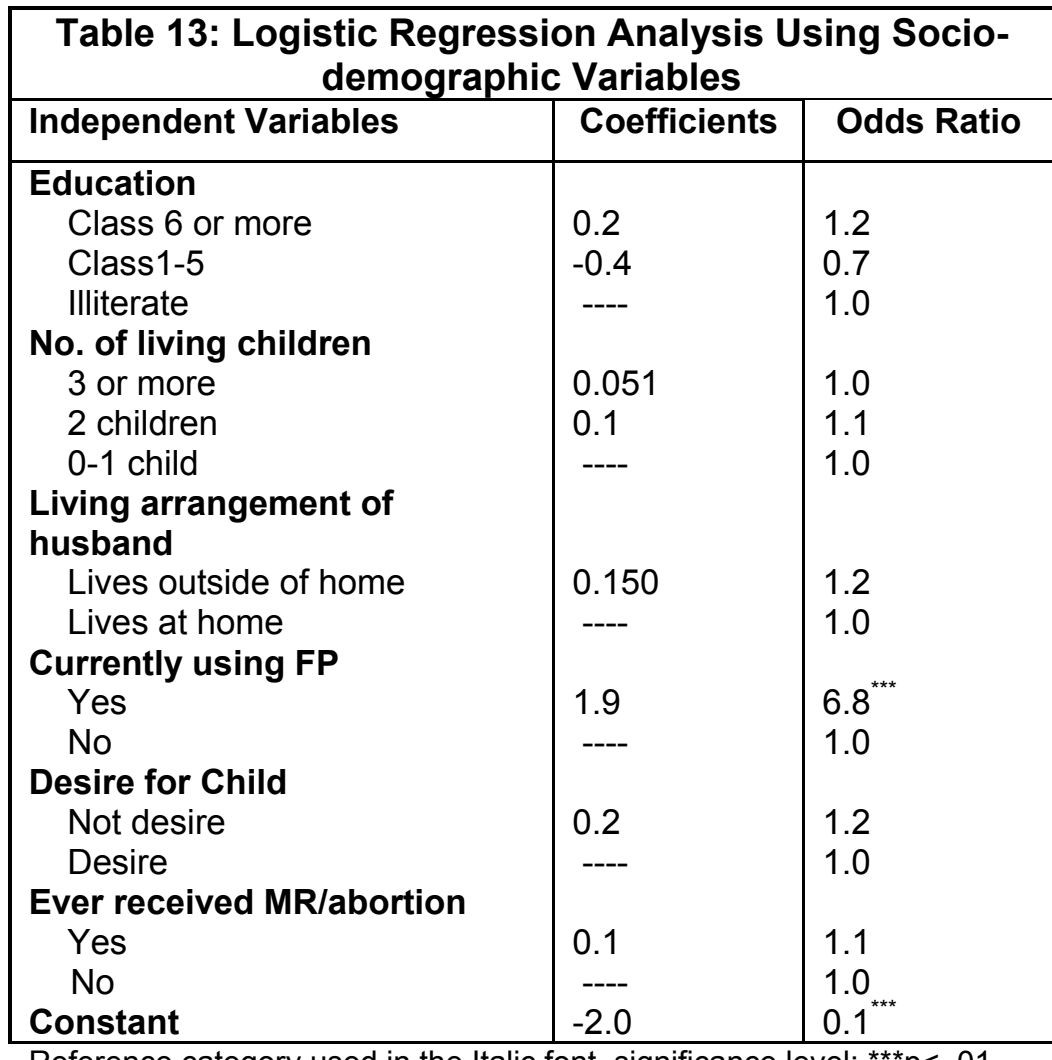

Reference category used in the Italic font, significance level: ${ }^{* *} p<.01$ time she was practicing family planning compared to those who were not using contraception. 


\section{Programmatic Variables}

In the second model, mainly programmatic variables were used. The four variables that were considered in the second model include the provision of an ECP as a prophylactic or on-demand, provision of an ECP brochure, whether the woman read the brochure and whether the woman showed the brochure to her husband. Findings of the logistic regression analysis show that the first three programmatic variables are important determinants of ECP use.

\begin{tabular}{|l|l|l|}
\hline \multicolumn{3}{|c|}{$\begin{array}{c}\text { Table 14: Logistic Regression Analysis } \\
\text { Using Programmatic Variables }\end{array}$} \\
\hline Independent Variables & $\begin{array}{l}\text { Coeffici } \\
\text { ents }\end{array}$ & $\begin{array}{l}\text { Odds } \\
\text { Ratio }\end{array}$ \\
\hline $\begin{array}{l}\text { Programmatic variables } \\
\text { Study area } \\
\quad \text { Prophylactic } \\
\quad \text { On-demand }\end{array}$ & 1.6 & $4.9^{* * *}$ \\
$\begin{array}{l}\text { Received brochure } \\
\text { Yes }\end{array}$ & -- & 1.0 \\
$\quad$ No & 1.7 & $5.7^{* * *}$ \\
$\begin{array}{l}\text { Read the brochure } \\
\text { Read }\end{array}$ & -- & 1.0 \\
$\quad$ Not read \\
$\begin{array}{l}\text { Brochure shown to } \\
\text { husband }\end{array}$ \\
$\quad 1.2$ & $3.3^{* * *}$ \\
$\quad$ Yes & -- & 1.0 \\
Constant & & \\
\hline Ron & 0.5 & 1.7 \\
& -- & 1.0 \\
\end{tabular}

Reference category used in the Italic font, significance level: ${ }^{* * *} p<.01$
The odds ratio values show that the chance of ECP use is about five times higher if ECP is provided as a prophylactic and/or women are provided with a brochure (odds ratio 5.7). Having read or having someone read the brochure to her also contributed positively and the odds ratio for this variable was estimated to be 3.3 $(\mathrm{p}<.01)$. Showing the brochure to her husband perhaps also indicates free communication between

\begin{tabular}{|c|c|c|}
\hline Independent Variables & Coefficients & $\begin{array}{l}\text { Odds } \\
\text { Ratio }\end{array}$ \\
\hline $\begin{array}{l}\text { Who takes decision to contact } \\
\text { doctor } \\
\text { Self } \\
\text { Mutual } \\
\text { Husband/Elder } \\
\text { Husband helps in household work } \\
\text { (Index) } \\
2 \text { or less work } \\
3 \text { or more work } \\
\text { Does not help } \\
\text { Working for payment } \\
\text { Yes } \\
\text { No } \\
\text { ECP Brochure shown to husband } \\
\text { Yes } \\
\text { No } \\
\text { Reported physical violence by } \\
\text { husband } \\
\text { No } \\
\text { Yes } \\
\text { Constant }\end{array}$ & $\begin{array}{l}0.2 \\
0.8 \\
---- \\
0.4 \\
---- \\
1.7 \\
----\end{array}$ & $\begin{array}{l}1.7^{*} \\
1.1 \\
1.0 \\
\\
1.3^{* \star} \\
2.3^{* *} \\
1.0 \\
1.5^{*} \\
1.0 \\
5.3^{* * *} \\
1.0\end{array}$ \\
\hline
\end{tabular}

Reference category used in the Italic font, significance level: ${ }^{* * *} p<.01$, ${ }^{* *} p<.05$

husband and wife at least on contraceptive use also had a positive effect on ECP use. As the 
finding shows, the chance of ECP use was almost twice (odd ratio value 1.7) as great when the brochure was shown to her husband and statistically the result was significant $(\mathrm{p}<.05)$.

\section{Gender Relations and}

\section{Women's Empowerment}

To explore how gender relations in the family influence use of ECP, five variables were used including decision-making power to seek medical treatment, husband helping wife in household work that is traditionally associated with women, working for payment, absence of physical violence by the husband, and the ECP brochure was shown to her husband.

In the families with more egalitarian gender education, chances of ECP use are 2.6 times higher than the less egalitarian,

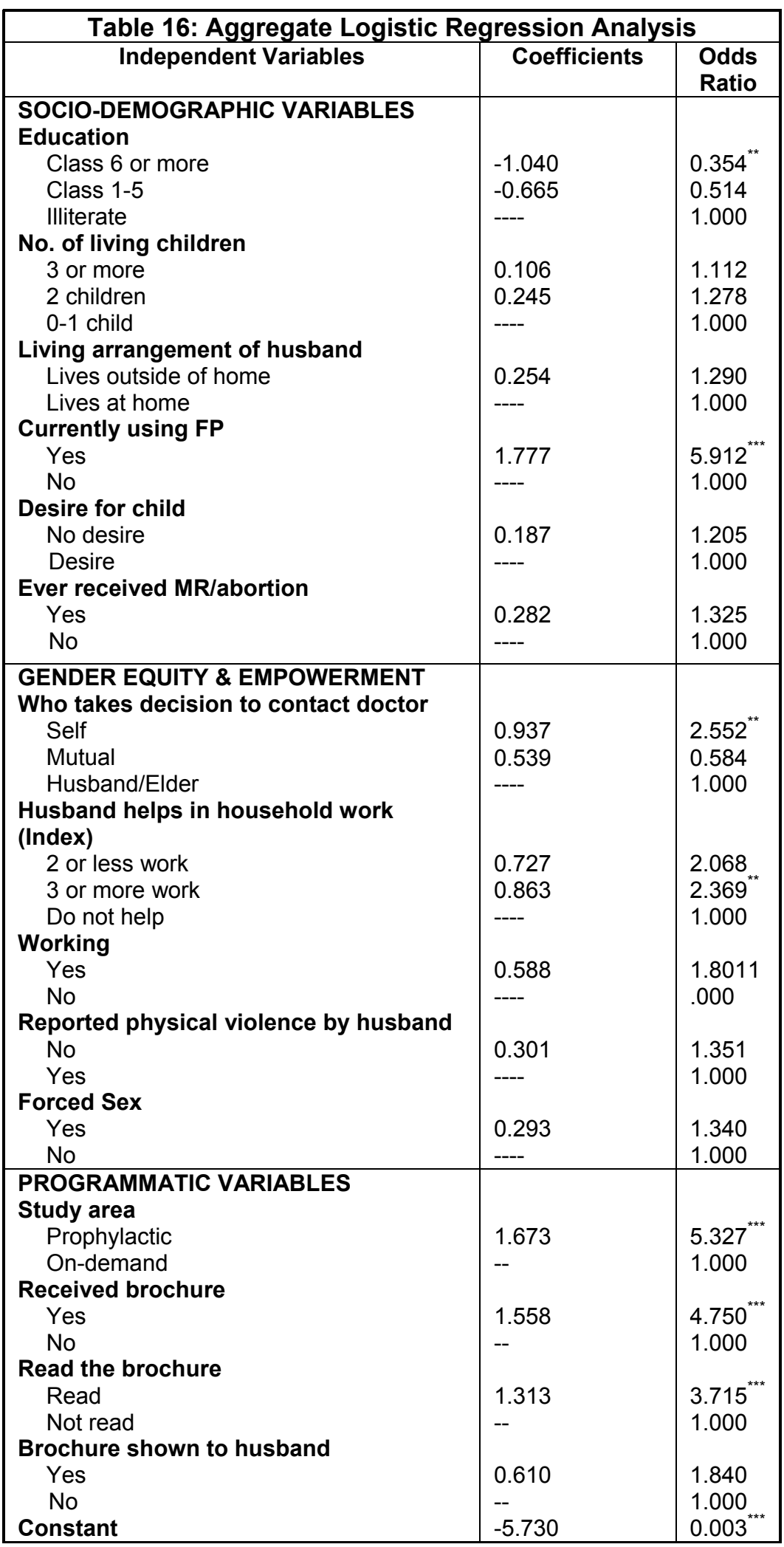

Reference category used in the Italic font, significance level: ${ }^{* * *} \mathrm{p}<.01$, ${ }^{* *} p<.05$ 
gender rigid family relationships. Analysis further indicates that women who have shown the brochure to their husbands have 5.3 times higher probability to use ECP than those who did not. This variable perhaps indicates better communication between husband and wife on contraception and other sexual matters. Working for payment and absence of violence also have positive relationships but are statistically not significant.

\section{Aggregate Analysis}

In the final run, all the variables were included to see how when all the variables work simultaneously which variables play a more critical role in the use of ECP. As the findings show, the variables which were found significant included one demographic variable (current use of family planning, odds ratio 5.9), two gender and empowerment variables (take decisions in the family, odds ratio 2.6, and having better gender relations in the family, odds ratio 2.4) and three programmatic variables (provision of ECP as prophylactic, odds ratio 5.3, provision of ECP

brochure, odds ratio 4.7, and reading of brochure, odds ratio 3.7). In total, while family environment and better gender equity play facilitating roles, programmatic variables play a much more significant and critical role in using ECP. Provision of ECP as a prophylactic and IEC activities (here the proxy of provision of brochure) are the key factors and should be given special attention in scaling up of the ECP program.

\section{Use Effectiveness}

Analysis for use effectiveness revealed that about 96 percent (96.6\% in prophylactic and 94.3\% in on-demand areas) of the women were able to prevent pregnancy after the use of ECP. Among those who used ECP correctly, the success rate for preventing pregnancy was almost 99 percent as against those who did not follow the full instructions correctly at 90 percent. Only 56 percent in the prophylactic area and 54 percent in the on-demand area had used ECP correctly (meaning they correctly followed the four points of ECP use). Among those who did not do anything to avoid pregnancy from unprotected sex, the incidence of unwanted pregnancy was much higher $(14.9 \%)$.

Overall, the number of unwanted pregnancies and pregnancies aborted were very small and hence no serious attempt was made to assess the impact of ECP use on abortion. Yet the data 
suggests that if ECP is used correctly, it may reduce abortion significantly. For instance, out of 85 women who used ECP correctly, only one became pregnant and she continued with the pregnancy. In contrast, out of 298 women who did not use ECP correctly or did not do anything to avoid pregnancy from unprotected sex, 40 (13.4\%) women became pregnant. Out of these 40, 25 women continued with their pregnancy, while 15 resorted to abortion. In other words, 37.5 percent of the pregnancies resulting from unprotected intercourse were aborted. This may be the factor by which the correct use of ECP could reduce abortion. In view of the limited data this conclusion, however, should be taken with caution.

\section{Side Effects}

Among those who used ECP, about 48 percent reported some kind of side effect. Among the side effects, 51 percent experienced nausea, 26 percent vomiting, 31 percent headache, 36 percent fatigue and 52 percent dizziness. Other side effects (menstrual problems and fatigue) were less frequently seen among the clients. None of these side effects lasted for more than one to two days, and no medication was required. The frequency and incidence of side effects was almost the same as has been reported in the WHO manual (WHO 1998).

\section{Diffusion of ECP}

\section{Information}

Beside family planning workers who were mentioned by every woman as a source of information, about 12.4 percent of the women had received ECP information from one additional person. A small number (1.9\%)

\begin{tabular}{|c|c|c|c|}
\hline \multicolumn{4}{|c|}{$\begin{array}{l}\text { Table 17: Reception and Dissemination of ECP } \\
\text { Information }\end{array}$} \\
\hline \multirow{3}{*}{$\begin{array}{c}\text { Selected } \\
\text { Characteristics }\end{array}$} & \multicolumn{3}{|c|}{ Service Delivery Options } \\
\hline & \multicolumn{2}{|c|}{ Experimental } & \multirow{2}{*}{$\begin{array}{c}\text { Total } \\
\text { Experimental }\end{array}$} \\
\hline & Prophylactic & $\begin{array}{c}\text { On- } \\
\text { Demand }\end{array}$ & \\
\hline \multicolumn{4}{|c|}{$\begin{array}{l}\text { Reception of Information about ECP from Other than FP } \\
\text { Workers }\end{array}$} \\
\hline 0 & 87.8 & 82.4 & 85.7 \\
\hline 1 & 10.9 & 14.7 & 12.4 \\
\hline $2+$ & 1.3 & 2.9 & 1.9 \\
\hline$\overline{\mathbf{N}}$ & 1019 & 665 & 1684 \\
\hline \multicolumn{4}{|c|}{ Dissemination of information about ECP } \\
\hline $\begin{array}{l}\text { Did not } \\
\text { disseminate }\end{array}$ & 76.7 & 69.5 & 73.9 \\
\hline $\begin{array}{l}\text { Disseminate } \\
\text { information }\end{array}$ & 23.3 & 30.5 & 26.1 \\
\hline $\mathbf{N}$ & 1019 & 665 & 1684 \\
\hline \multicolumn{4}{|c|}{ No. of Person to Whom Information was Disseminated } \\
\hline 1 & 24.9 & 45.8 & 34.5 \\
\hline 2 & 18.1 & 20.2 & 19.1 \\
\hline 3 & 19.4 & 14.8 & 17.3 \\
\hline 4 & 10.5 & 6.4 & 8.6 \\
\hline 5 & 9.3 & 7.4 & 8.4 \\
\hline $6+$ & 17.6 & 5.4 & 12.1 \\
\hline Mean & 3.5 & $2.3^{* *}$ & 2.9 \\
\hline SD & 2.4 & 1.8 & 2.2 \\
\hline $\mathbf{N}$ & 237 & 203 & 440 \\
\hline
\end{tabular}


reported receiving information from two or more persons. Of those who received information about ECP, slightly more than a quarter disseminated it to other persons. While they received information on ECP from an average of 0.4 person (other than family planning workers), they disseminated information on ECP to an average of three persons. Findings showed that women in the prophylactic area have disseminated information about ECP to a significantly greater number of people than those in the on-demand area $(\mathrm{p}<.05)$ (See Table 17).

The audience of dissemination of ECP information was diverse, from friends to relatives, home to village, and even to smaller towns, or to villages in another district. Table 17 shows how they received and disseminated the ECP information. Clearly while it shows that informal dissemination of information about ECP among women was fast, the quality and accuracy of information disseminated could not be assessed.

\section{Willingness to Pay}

During the diagnostic phase, both from FGD and in-depth case studies, it was apparent that women were interested in a method which could protect them from unwanted pregnancy if unprotected intercourse occurred. Most of them were willing to pay for such a method and often they said they would buy the method even if the cost were as high as 50, 100 and 200 Taka. During the diagnostic phase they were not aware of the actual method and they were replying to a hypothetical question, so the accuracy of their answers was questionable. Many of them had quoted a much higher price as they were comparing it with the cost of undergoing MR or an abortion. At the time of the evaluation, the women were more aware of the method and had a better idea as to what it could do. Hence, at the time of the evaluation a more systematic attempt was made to assess women's willingness to pay for the method.

To assess the amount which is reasonable to charge and women are willing to pay, each woman was asked whether she was willing to pay 10 Taka $(\$ 0.17)$ for one cycle of ECP (that could be used for one episode of unprotected

\begin{tabular}{|l|c|c|c|}
\hline \multicolumn{4}{|c|}{$\begin{array}{c}\text { Table 18: Women's Willingness to Pay for } \\
\text { the Method }\end{array}$} \\
\hline \multicolumn{4}{|c|}{ Percentage Willing to Pay } \\
\hline $\begin{array}{l}\text { Taka 15 or } \\
\text { more }\end{array}$ & Taka 10 & Taka 5 & Taka 1-4 \\
\hline 60.9 & 9.0 & 19.0 & 11.1 \\
\hline
\end{tabular}
intercourse). If she replied positively, the amount was increased to 15 Taka $(\$ 0.26)$ and she was 
questioned whether she would be willing to buy the method at the increased price. If she still showed her readiness, she was probed for the maximum price she would be willing to pay for the method. Those who refused to pay Taka 10 were given an option of Taka 5. If they still expressed their unwillingness, they were probed for the minimum price at which they were willing to pay. Their willingness to pay are analyzed and presented in Figure 9.

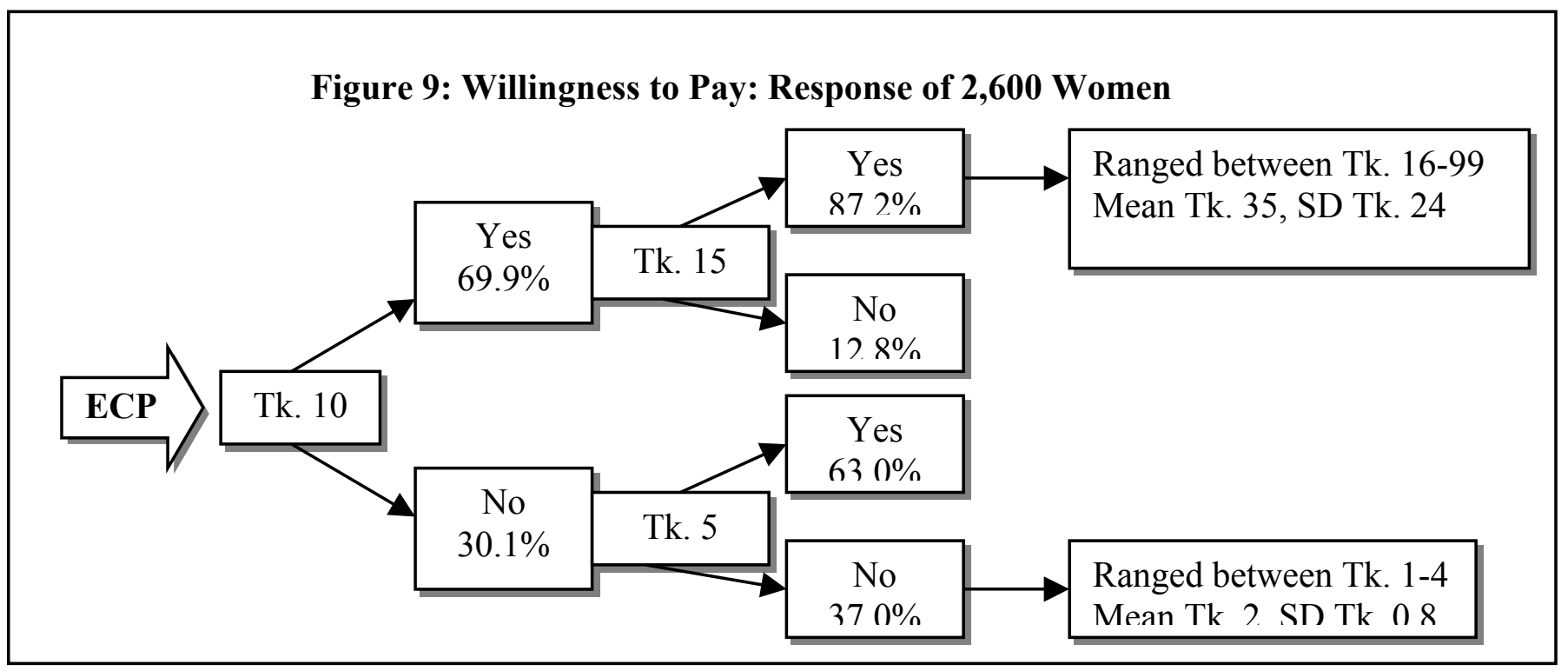

The analysis shows that around 70 percent of the women were willing to pay Taka 10 (\$0.17) for the method. Among them, 87 percent were ready to pay even Taka 15 (\$0.26). Among the 30 percent of women who expressed their unwillingness to pay Taka 10 for the method, two-thirds were ready to pay Taka $5(\$ 0.08)$. The remaining women were willing to pay between Taka 1-4, averaging around Taka 2.

\section{DISSEMINATION AND UTILIZATION OF THE STUDY}

Right from the planning stage of the study, the utilization of the research findings and scaling up of ECP in the National Family Planning Program were strategically targeted. Accordingly, while planning the details of the study and its implementation, the Directorate of Family Planning was involved at each stage. Progress on implementation was regularly reviewed by the Project Management Committee, chaired by the Director, $\mathrm{MCH}$ and Line Director, Essential Services Package Program covering MCH, Family planning and Reproductive Health Services. 
The Ministry of Health and Family Welfare was also interested in introducing ECP in the National Family Planning Program if the study showed that it was feasible and acceptable. Thus during the study, the MOHFW was in constant touch.

To keep all the stakeholders informed about the study and emerging findings, two UPDATES were printed and widely distributed. Based on the primary findings of the study, a presentation was made in the Ministry of Health and Family Welfare, chaired by the Additional Secretary and attended by another 20 senior officials of the Ministry, the UNFPA representative and other CAs. Soon, following this meeting, a workshop was organized where the preliminary findings of the

OR project were again presented and the usefulness of introducing ECP in the National Family Planning Program was openly discussed. More than 60 professionals, government officials, UN agencies, donors and media representatives participated in the meeting. Consensus emerged that ECP is an important reproductive health intervention. It is feasible to introduce in the National Program and no further information is required to make this policy decision. National newspapers published the proceedings of the workshop, wrote articles on ECP and helped in creating a conducive

\section{Box 3: Key Decisions of MOHFW, Government of Bangladesh for Introduction of ECP in the National Family Planning Program}

1. It can be introduced according to the recommendation of the 40th meeting of the National Technical Committee.

2. Training on ECP should be given according to the Population Council tested model and it should be given along with the present training program being given for the essential service package (ESP).

3. At first, half day training of trainers (TOT) could be provided with the technical assistance from the Population Council. District level officers (who are involved in training on ESP) should be given this training.

4. Before introduction of ECP in the whole country, initially it should be introduced in the Dhaka Division.

5. As suggested in the UNFPA proposal, UNFPA could be requested to supply Postinor-2. Moreover, as a part of their technical assistance, the responsibility of supply of transparency sets (for training), teaching aids brochures, TOT manuals and carrying out economic evaluation (of introducing ECP in the National Program) should be entrusted to the Population Council.

6. Collaborating organizations such as Pathfinder International and John Snow Incorporation can be requested to train NGOs and their staff on ECP and the Population Council can be asked to provide technical assistance in this effort.

7. Among the two pill brands, Postinor-2 and repackaged ECP could be charged Taka 8 and 3 respectively.

Source: No: PAKAU-1/ECP/22/2001/248 Date: 29/12/2001

environment for its introduction in the program. 
Soon, the Directorate of Family Planning requested the MOHFW to approve the introduction of ECP in the National Family Planning Program, which in the light of the positive findings of the present OR study was accepted. The MOHFW, besides approving introduction of ECP in the National Family Planning Program, recommended that ECP be introduced in a phased manner and in the first phase, it should be introduced in Dhaka Division covering a population of about 52 million. The Ministry also requested the FRONTIERS Program of the Population Council to provide technical assistance in introducing ECP in the National Program. The key points of the government's decision are given in Box 3 and the true copy of the government order is included in Appendix A.

UNFPA, with whom a partnership was maintained for introducing ECP, agreed to provide the required funding to the Government of Bangladesh to conduct the training of service providers in ECP and to supply the requisite amount of ECP. After a comparative assessment of the available ECPs, Postinor-2 was selected for provision of ECP through the National Family Planning Program. According to the Government's decision, 8 Taka will be charged for one packet of Postinor-2.

The initial thought that available oral contraceptive pills in the local market could be repacked as ECP and promoted as a special brand was dropped because of administrative problems and fear of confusion among the OCP users. For the same reason, it was also decided that in the educational campaign of ECP, no mention would be made that available oral pills contraceptive could also be used as ECP.

The findings of the study have been presented in more than a half dozen international meetings in various countries including USA, India, Nepal, and Thailand. FRONTIERS is working closely with the Family Health Division, Government of Nepal to introduce ECP in their national FP program. Findings of the study and insights on how OR has been successfully translated into action have been prepared and put on the DFID website to inspire others. 


\section{SCALING UP: PROGRESS MADE}

FRONTIERS has developed, tested, printed and provided to the Directorate of Family Planning adequate copies of:

- Trainers manual on ECP both in English and Bangla languages

- Teaching aids and transparencies sets

- Brochure for providers and clients

FRONTIERS staff in collaboration with the Directorate of Family Planning have trained 50 master trainers and 900 trainers. In turn, these trainers have trained about 15,000 grass-root providers. ECP is now being provided by the grass-root workers at a cost of Taka 8 (\$0.13) per two pills packets, in 17 districts, covering a population of 52 million. FRONTIERS staff are now helping in modifying the MIS system and working with the Directorate of Family Planning to monitor the introduction program ${ }^{1}$.

\section{CONCLUSIONS AND RECOMMENDATIONS}

This study was undertaken to examine the feasibility of introducing emergency contraceptive pills in the National Family Planning Program and its acceptability among Bangladeshi women. The attempt was also made to address many of the operational questions, which need to be answered before introducing the method in the national program. The three key operational questions include:

- What should be the content and duration of training?

- Could grass-root workers impart ECP education correctly to their clients? Should grassroot workers be used for providing ECP services?

- Can service providers encourage their clients to use a regular contraceptive method after using ECP?

A multi-factorial control group, post intervention survey design was used to study the effect on the acceptability and use of ECP. The study tested the relative effectiveness of providing ECP as a prophylactic against supplying it on-demand after unprotected intercourse has occurred. Sukhi,

\footnotetext{
${ }^{1}$ At the time this report was going to print, the ECP program has been expanded in the entire country and providers training will be completed by January 2005 .
} 
a low dose combined oral product, commonly used as oral contraceptive pills in Bangladesh was provided as ECP after repackaging it in a specially designed envelop.

The findings clearly indicate that ECP will have high acceptability among women. In Bangladesh, where unprotected intercourse is common, women are very interested in a method, which could protect them from unwanted pregnancy. A qualitative study in the preparatory phase showed that in the absence of the knowledge of ECP, women desperately try various traditional and ineffective methods to avoid pregnancy from unprotected intercourse. Some of the traditional methods women use are quite harmful to their health.

A two-day training model developed for the present study and a half-day reorientation meeting, one month after the training, was found very effective. During the training, besides information on ECP, the providers were also provided with a contraceptive technology update and counseling skills. The half-day orientation, one month after the training, was for clarifying their concerns and doubts about the method. An evaluation of their knowledge before training, immediately after training, and 4 months after training revealed the effectiveness of the training. More than 90 percent of the providers, four months after training were able to answer all key questions related to the method and its correct use. Further, observations on the counseling by the providers to their clients revealed that all the providers including grass-root workers, many of whom have only limited schooling, were able to educate and impart ECP services to their clients correctly. This indicates that they had assimilated the ECP knowledge given to them during the training. This is an encouraging finding as it supports involvement of all categories of health and family planning workers in the provision of ECP. This would enhance the wide accessibility of ECP even in the remote rural areas.

The training manual, teaching aids and ECP brochure developed for providers and clients during the study have been adopted by the Directorate of Family Planning to use during scaling up of ECP in the National Family Planning Program. This reflects the usefulness of these educational materials and effectiveness of the training model developed under the project. 
Findings from the endline survey of 3900 women, 1300 each from the prophylactic area, ondemand area and control area, revealed that both knowledge of ECP and its use was far better in the prophylactic area as compared to the on-demand area. In the control area the knowledge and use of ECP remained at a negligible level. When ECP was provided as a prophylactic, it was used when the necessity arose. In the on-demand areas women faced obstacles in obtaining ECP after unprotected intercourse. Besides, their hesitation (because of the sensitivity of the issue) to go to providers and ask for ECP soon after unprotected intercourse, the non-availability of providers at home, and the lack of time to go to the provider for ECP supply were some of the common barriers. This indicates that at least at the initial stage of the introduction of ECP in the national program, its provision as prophylactic would be a better choice.

Analysis of the knowledge of ECP provided important clues to the possible problems if a wellplanned educational campaign is not made an integral part of the introduction of ECP in the national program. The findings revealed that while a varying percentage (30-50\%) of women had correct knowledge of the four components of ECP use - number of doses, pills per dose, interval between two doses, and the time limit within which the first dose of pill must be taken. Less than one-fifth of the women had correct knowledge of all the four components of ECP use.

Information on ECP was provided through counseling by family planning workers and distributing the ECP brochure among potential users. The evaluation however showed that many women did not receive the brochure. The provision of the ECP brochure seems to be an effective way to educate couples about the method. It was observed that a larger proportion of women who had received the brochure had correct knowledge of ECP use as compared to those who had not received the brochure. The importance of strong educational campaign also reflects the fact that among those who used ECP after unprotected intercourse, only half used it correctly. The most common mistake was passing the time limit before which the first dose of ECP must be taken after unprotected intercourse. All this underlines that, while introducing ECP in the national program, a strong educational campaign must be planned and effectively implemented. Different channels should be used to reach all potential clients and reinforce the messages on ECP use. 
Of the women who were aware of ECP, had an unprotected intercourse and did not want a child in the near future, 65 percent used ECP to protect themselves from unwanted pregnancy. This proportion was significantly higher in the prophylactic area (75 percent) than in the on-demand area (47 percent). Further, 99 percent of those who had used ECP correctly succeeded in avoiding unwanted pregnancies. This success rate dropped to 90 percent if they had used ECP incorrectly (often delayed more than 72 hours in taking the first dose). Among those who did not do anything after unprotected intercourse or were not aware of ECP, 13 percent of the women became pregnant. This demonstrates that correct use of ECP could substantially reduce unwanted pregnancies and demand for MR or abortion. Data collected for this study indicates that correct use of ECP could reduce abortion by almost 37 percent. This is a significant finding as a one-third reduction in unwanted pregnancies and in the number of abortions would contribute greatly to reducing maternal mortality and morbidity in the country ${ }^{2}$. This finding is quite similar to the WHO study (2001), which estimated that use of ECP in China could reduce abortion by 50 percent.

Application of a logistic regression model to identify the determinants of ECP use showed that programmatic factors are the key determinants of ECP use. According to the analysis, the probability of using ECP is 5 times higher if provided as prophylactic, 5 times higher if provided with a brochure and almost 6 times higher if the woman was already using some contraceptive method. Contextual parameters like better gender equity in the family, women's empowerment and absence of violence by husbands also improved the chance of ECP use by creating a better and conducive environment within the family. However, while the odds ratio of these parameters are positive and statistically significant $(\mathrm{p}<.05)$, their overall influence as determinants of ECP use is less significant than the programmatic factors. The policy implications of these findings are clear.

While women need ECP to avoid pregnancy from unprotected intercourse, its effective use will depend on two key factors - the mode of delivery (prophylactic or on-demand) and the effectiveness of educational campaign to promote the correct use of ECP. Lack of educational campaigns will not only keep ECP use at a low level but will also reduce its effectiveness. As we

\footnotetext{
${ }^{2}$ Due to small sample size this finding should be taken with caution.
} 
observed earlier, if the method is correctly used, chances of its success in avoiding unwanted pregnancies from unprotected intercourse are as high as 99 percent.

The fear that wide publicity and easy accessibility of ECP may encourage women to use ECP as regular contraceptive method was not supported by this study. The findings show that while 84 percent of the women were using some family planning method before using ECP, contraceptive use increased to 91 percent after ECP use. Further analysis revealed that most (96\%) of those who used ECP because of failure in using a contraceptive method (e.g., missing pills, leakage of condom) reverted to contraception as their routine form of prevention against pregnancy. More significantly, however, is the fact that some of them who were not using any contraceptive method before the use of ECP adopted contraception after ECP use.

The study revealed that the side effects of ECP as reported by the women were quite similar to the side effects mentioned by WHO (1998) for combined EC pill such as nausea (51\%) and vomiting $(26 \%)$. However, reported side effects were minor and none of them last more than a day or two.

It is encouraging to note that the positive findings of the study have helped the Ministry of Health and Family Welfare approve the use of ECP in the National Family Planning Program and now it is being scaled up in the Dhaka Division, covering a population of 52 million. It is hoped that while scaling up, the lessons learned from this study will be used. The critical elements are the IEC campaign to enhance correct knowledge and use of the method and the provision of ECP as a prophylactic to enhance accessibility and use of ECP.

The government's decision to charge Taka 8 for the ECP may be a beginning of an effort on cost recovery for the services provided by the public clinics. Close monitoring of the scaling up efforts will provide more useful information on the introduction of ECP in national program, not only for Bangladesh ECP program but for the neighboring countries of South Asia also. Finally, the present study is a good demonstration of how operations research can contribute in policy decision and how research findings can be translated into action. 


\section{REFERENCES}

Akhter, Halida. H. 1986. "Medical Practice after Legalization of Abortion: Bangladesh." Prevention and Treatment of Contraceptive Failure, U. Landy and S. S. Ratnam (eds.). New York: Plenum Press.

Bangladesh Bureau of Statistics. 1997. Gender Statistics in Brief 1997. Monograph. Dhaka: Bangladesh Bureau of Statistics.

Bangladesh Bureau of Statistics. 2001. Statistical Pocketbook. Dhaka: Bangladesh Bureau of Statistics.

Chowdhury, Syeeda Nahid Mukith, Sharif MI Hossain and Nazmul Huda. 1998. Knowledge, Attitude and Practices on EC among Selected Health Care Providers and Drug Sellers in Dhaka City. In Emergency Contraception Workshop Proceeding. Dhaka, Bangladesh: Population Council.

Chowdhury, T. A. 1998. Emergency Contraception: Service Providers Concern and Considerations. In Emergency Contraception Workshop Proceeding. Dhaka, Bangladesh: Population Council.

International Consortium for Emergency Contraception. 2002. Expanding Global Access to Emergency Contraception: A Collaborative Approach to Meeting Women's Needs. New York: International Consortium for Emergency Contraception.

Kamal, H., A. Hussain, S. F. Begum, and G. M. Kamal. 1993. Prospects of Menstrual Regulation Services in Bangladesh: Results of an Operations Research. Monograph. Dhaka: Bangladesh Association for Prevention of Septic Abortion (BAPSA).

Khan M. E. and Sharif MI Hossain. 2001. Introducing Emergency Contraception in Bangladesh. Research Update No 1. Dhaka, Bangladesh: Population Council.

Khan, M. E. and Sharif Mohammed Ismail Hossain. Training Service Providers on Emergency Contraception: Lessons Learned from an OR Study. Research Update 2, July 2001. Dhaka, Bangladesh: Population Council/FRONTERS.

NIPORT, Mitra and Associates and Measure/DHS+IRC-Macro International Inc. 2000. Bangladesh Demographic and Health Survey 1999-2000: Preliminary Report. Dhaka, Bangladesh: NIPORT, Mitra and Associates and Measure/DHS+ ORC-Macro International Inc.

Rochat, R. W., S. Jabeen, M. J. Rosenberg, A. R. Measham, A. R. Khan, M. Obaidullah and P. Gould. 1981. "Maternal and Abortion Related Deaths in Bangladesh, 1978-79." International Journal of Gynaecology and Obstetrics 19: 155-164. 
Singh, Susheela, Josefina V. Cabigon, Altaf Hossain, Haidary Kamal and Aurora E. Perez. 1997. "Estimating the Level of Abortion in the Philippines and Bangladesh." International Family Planning Perspectives, 23: pp100-107 \& 144.

UNDP/UNFPA/WHO/World Bank Special Programme of Research, Development and Research Training in Human Reproduction. 2001. Use of Emergency Contraception Pills could Halve the Induced Abortion Rate in Shanghai, China. Social Science Research Policy Briefs. Series 2. No 1.

World Health Organization. 1998. Emergency Contraception: A Guide for Service Delivery. WHO/FRH/FPP/98.19. Geneva: WHO. 


\author{
APPENDIX \\ (True copy) \\ Government of the People's Republic of Bangladesh \\ Ministry of Health and Family Welfare \\ Section: Development 1
}

No: PAKAU-1/ECP/22/2001/248

Date: $29 / 12 / 2001$

Subject: Related with the Introduction of Emergency Contraceptive in the National Family Planning Program

Source (Reference): Directorate of Family Planning Memo No. DFP/ESP/FPS/EC -231/98/1323, date 20/8/2001

With reference of the above-mentioned subject and source to introduce Emergency Contraceptive Pills in the National Family Planning Program, the proposal of collection and distribution of Emergency Contraceptive Pill has been approved by the direction under the following conditions.

1. It can be introduced according to the recommendation of the 40th meeting of the National Technical Committee.

2. Training on ECP should be given according to the Population Council tested model and it should be given along with the present training program being given for essential service package (ESP).

3. At first, half day training of trainers (TOT) could be provided with the technical assistance from Population Council. District levels officers (who are involved in giving training on ESP) should be given this training.

4. Before introduction of ECP in the whole country, initially it should be introduced in the Dhaka division.

5. As suggested in UNFPA proposal, UNFPA could be requested for the supply of Postinor-2. Moreover, as a part of their technical assistance, the responsibility of supply of transparency sets (for training), teaching aids brochures, TOT manuals and carrying out economic evaluation (of introducing ECP in the National Program) should be entrusted on Population Council.

6. Collaborating organizations such as Pathfinder International and John Snow Inc. can be requested to train NGOs and their staffs on ECP and Population Council can be asked to provide technical assistance in this effort.

7. Among the two pill brands, Postinor-2 and repackaged ECP could be charged as Taka 8 and 3 respectively.

8. Postinor-2 and repackaged OCP should be distributed as ECP in a special package (meaning as a special brand).

9. Initially, ECP program should be closely monitored for one year before its introduction in the whole country. Based on the observation changes should be made in the distribution system, if required.

Signature

A. H. M. Towhidul Islam Sr. Assistant Secretary Ministry of Health and Family Welfare

Director General

Directorate of Family Planning

Azimpur,

Dhaka

(.......) - Text inside the bracket added by us only for clarification 